Brazilian Journal

of Chemical

Engineering

\title{
ON THE PERFORMANCE OF DIFFERENT RANS BASED MODELS TO DESCRIBE THE TURBULENT FLOW IN AN AGITATED VESSEL USING NON-STRUCTURED GRIDS AND PIV VALIDATION
}

\author{
Alejandro Alonzo-Garcia ${ }^{1}$, Víctor X. Mendoza-Escamilla ${ }^{2}$, \\ Sergio A. Martinez-Delgadillo ${ }^{3 *}$, Israel Gonzalez-Neria ${ }^{3}$, \\ Claudia del C. Gutiérrez-Torres ${ }^{4}$ and José A. Jiménez-Bernal ${ }^{4}$ \\ ${ }^{1}$ Centro de Ingeniería y Desarrollo Industrial, Querétaro, Mexico. \\ ${ }^{2}$ Universidad Autónoma Metropolitana Azcapotzalco, Departamento Electrónica, México D.F., Mexico. \\ ${ }^{3}$ Universidad Autónoma Metropolitana Azcapotzalco, Departamento Ciencias Básicas, México D.F., Mexico. \\ E-mail: samd@correo.azc.uam.mx; ORCID: 0000-0002-3768-2696 \\ ${ }^{4}$ Instituto Politécnico Nacional, México D.F., Mexico.
}

(Submitted: March 3, 2018 ; Revised: May 2, 2018 ; Accepted: May 20, 2018)

\begin{abstract}
The performances of the Standard $\kappa-\varepsilon$, RNG, Realizable, $\kappa-\omega$ and RSM turbulence models to describe the behavior of the flow in agitated tank reactors were evaluated. Because most of these tanks have complex geometries, structured meshing schemes are not a practical alternative in engineering. Two particular unstructured meshing schemes composed of either Cartesian Cut-Cell (CC) or Tetrahedral elements were tested in domains larger than 3 million cells. In this work, the blade thickness, which is usually disregarded, was accounted for. The performance of the turbulence models was validated by PIV measurements. A strong dependence on the grid size and the power number was found, with CC grids having good agreement with grids $>3.6$ Million. The pumping number was independent of the cell number and the values agree with experimental data. The Realizable model resolved with a tetrahedral grid presented the overall best performance.

Keywords: Agitated tank; Pitched blade turbine, Cut-Cell; RANS; Tetrahedral cells; PIV.
\end{abstract}

\section{INTRODUCTION}

Agitated tank reactors are widely used in the processing engineering field to perform tailored heat transfer, chemical reactions, mixing, suspension and other desired operations. In most of the cases, the flow within an agitated tank is comprised of recognizable flow patterns which circulate the turbulent flow along the vessel (Aubin et al., 2001; Kresta and Wood, 1993). Such flow structures depend mainly on the impeller pumping nature given by its geometry and location relative to the vessel (Ge et al., 2014a; Mao et al., 1997). To assess the flow patterns in stirred tank reactors (STRs), different experimental and numerical techniques have been applied and developed. By experimental means, velocities and turbulent components have been obtained through Laser Doppler Velocimetry (LDV) or Particle Image Velocimetry (PIV) techniques. From the numerical point of view, turbulence could be modeled using powerful techniques such as Large Eddy Simulation (LES) or Direct Numerical Simulation (DNS). Both techniques are capable to predict the instantaneous and mean velocities and turbulent parameters in STRs (Alcamo et al., 2005; Sbrizzai et al., 2006). However, they demand considerable amounts of computational

\footnotetext{
*Corresponding author: Sergio A. Martinez-Delgadillo - E-mail: samd@correo.azc.uam.mx
} 
resources as the smallest dissipative temporal and spatial scales need to be fully resolved (DNS) or approximated with a sub-grid scale model (LES). Also, as statistical convergence must be reached for adequate mean values predictions, additional time steps must be performed. In this regard, the turbulence modelling based on the Reynolds average NavierStokes equations (RANS) is a more suitable option for practical engineering applications (Andersson et al., 2012). Further, just to point out two examples, LES sub-grid scale models (SGS) for multiphase flow, and those related to thermally affected boundary layers are not fully understood (Jiang and Lai, 2009), and engineering design simulations still rely on RANS modelling (Achouri et al., 2012; Ge et al., 2014; Kasat et al., 2008). Over the last two decades, a variety of works have been devoted to study the flow in STRs using RANS based turbulence models by means of the Multiple Reference Frame (MRF) and the Sliding mesh (SM) approaches mainly for Rushton turbines, PBT impellers and others. As shown in Table 1, which lists some representative work, different grid sizes and refinement, spatial discretization, and coupling algorithms, among others, have been employed (Aubin et al., 2004; Bhattacharya and Kresta, 2008; Coroneo et al., 2011; Jaworski and Zakrzewska, 2002; Joshi et al., 2011a, 2011b; Murthy and Joshi, 2008; Yeoh et al., 2004 ).

For example, Aubin et al. (2004) compared the Standard $\kappa-\varepsilon$ and Renormalization Group (RNG) models varying different discretization schemes using a grid of 155000 elements. Marginal differences

Table 1. CFD simulations comparing different approaches and RANS models.

\begin{tabular}{|c|c|c|c|c|c|c|}
\hline Authors & Impeller & $\begin{array}{r}\operatorname{Re} \\
\times 10^{3} \\
\end{array}$ & $\begin{array}{c}\text { Approach and } \\
\text { model }\end{array}$ & $\begin{array}{c}\text { \# Elements } \\
\times 10^{3} \\
\end{array}$ & $\begin{array}{c}\text { Blade } \\
\text { thickness }\end{array}$ & Parameters \\
\hline $\begin{array}{l}\text { Jaworski } \\
\text { and Zakrzewska } \\
(2002)\end{array}$ & PBT & 22.5 & $\begin{array}{l}\text { MRF } \\
\text { Standard } \kappa-\varepsilon \\
\text { RNG } \\
\text { Realizable } \\
\text { Chen-Kim } \\
\text { RSM }\end{array}$ & $\begin{array}{l}112 \\
\text { (hexahedral) }\end{array}$ & No & $\begin{array}{l}\text { Mean } \\
\text { velocities } \\
\text { TKE }\end{array}$ \\
\hline $\begin{array}{l}\text { Aubin } \\
\text { et al. (2004) }\end{array}$ & Rushton & 45 & $\begin{array}{l}\text { MRF, SM } \\
\text { Standard } \kappa-\varepsilon \\
\text { RNG }\end{array}$ & $\begin{array}{l}155 \\
\text { (hexahedral) }\end{array}$ & No & $\begin{array}{l}\text { Mean } \\
\text { velocities } \\
\text { TKE }\end{array}$ \\
\hline $\begin{array}{l}\text { Yeoh } \\
\text { et al. (2004) }\end{array}$ & Rushton & 40 & $\begin{array}{l}\text { SM } \\
\text { Standard } \kappa-\varepsilon\end{array}$ & $\begin{array}{l}490 \\
\text { (hexahedral) }\end{array}$ & Yes & $\begin{array}{l}\text { Mean } \\
\text { velocities } \\
\text { TKE, } \\
\text { Dissipation }\end{array}$ \\
\hline $\begin{array}{l}\text { Murthy } \\
\text { and Joshi (2008) }\end{array}$ & $\begin{array}{l}\text { PBT, } \\
\text { Rushton, } \\
\text { Hydrofoil }\end{array}$ & 45 & $\begin{array}{l}\text { SM } \\
\text { Standard } \kappa-\varepsilon \\
\text { RSM }\end{array}$ & $\begin{array}{l}575 \\
\text { (hexahedral) }\end{array}$ & No & $\begin{array}{l}\text { Mean } \\
\text { velocities } \\
\text { TKE }\end{array}$ \\
\hline $\begin{array}{l}\text { Coroneo } \\
\text { et al. }(2011)\end{array}$ & Rushton & 29 & $\begin{array}{l}\text { MRF } \\
\text { Standard } \kappa-\varepsilon\end{array}$ & $\begin{array}{l}270-6600 \\
\text { (hexahedral) }\end{array}$ & No & $\begin{array}{l}\text { Mean } \\
\text { velocities } \\
\text { TKE, } \\
\text { Dissipation }\end{array}$ \\
\hline Joshi et al. (2011a ) & Rushton & 45 & $\begin{array}{l}\text { MRF, SM, and } \\
\text { others } \\
\text { Standard } \kappa-\varepsilon \\
\text { RNG } \\
\text { Chen-Kim } \\
\text { RSM }\end{array}$ & $\begin{array}{l}85 \text { (MRF) } \\
100 \text { (SM) } \\
\text { (hexahedral) }\end{array}$ & No & $\begin{array}{l}\text { Mean } \\
\text { velocities } \\
\text { TKE, } \\
\text { dissipation }\end{array}$ \\
\hline Joshi et al. (2011b) & PBT & & $\begin{array}{l}\text { MRF SM } \\
\text { Standard } \kappa-\varepsilon \\
\text { RNG } \\
\text { RSM } \\
\text { SM }\end{array}$ & $\begin{array}{l}320 \\
\text { (hexahedral) }\end{array}$ & No & $\begin{array}{l}\text { Mean } \\
\text { velocities } \\
\text { TKE, } \\
\text { dissipation }\end{array}$ \\
\hline Singh et al. (2011) & Rushton & & $\begin{array}{l}\text { Standard } \kappa-\varepsilon \\
\text { k- } \omega \text { SST } \\
\text { k- } \omega \text { SST-CC } \\
\text { SAS-SST } \\
\text { RSM }\end{array}$ & $\begin{array}{l}2.13 \mathrm{M} \\
\text { (hexahedral) }\end{array}$ & No & $\begin{array}{l}\text { Mean } \\
\text { velocities, } \\
\text { TKE, } \\
\text { dissipation }\end{array}$ \\
\hline Lane (2017) & A310 Hydrofoil & & $\begin{array}{l}\text { SM } \\
\text { Standard } \kappa-\varepsilon \\
\text { k- } \omega \text { SST } \\
\text { k- } \omega \text { SST-CC } \\
\text { DES }\end{array}$ & $\begin{array}{l}3-28 \mathrm{M} \\
\text { Hybrid }\end{array}$ & Yes & $\begin{array}{l}\text { Mean } \\
\text { velocities, } \\
\text { TKE, } \\
\text { dissipation }\end{array}$ \\
\hline
\end{tabular}


between the predictions derived from the MRF and the SM simulations were found. Thus, the inclusion of the temporal term is not always justified in terms of computational expenses. Also, the performances of both turbulence models were similar, and in both cases, underestimated values of turbulence kinetic energy (TKE) were found. Yeoh et al. (2004) performed a comparison between LES and SM simulations using the Standard $\kappa-\varepsilon$ model with a grid composed of 490000 elements. Important underprediction of TKE and severe deviations for the turbulence dissipation rate $(\varepsilon)$ were reported. The total content of the dissipated energy was about $45 \%$ below the experimental value. Coroneo et al. (2011), studied the flow induced by a Rushton turbine using the Standard $\kappa-\varepsilon$ model, stating the importance of the cell number on the turbulence levels and, hence, the quality of the predictions. According to these authors, the estimation of the integral content of dissipated power could be improved if finer grids are used. Joshi et al. (2011a and 2011b) reported a full description of the capabilities of several RANS based models, reporting important deviations between the RNG and Standard $\kappa-\varepsilon$ model predictions of TKE production and dissipation rates. The authors stated that the Standard $\kappa-\varepsilon$ model performs well in unidirectional flow regions with weak recirculation such as those caused by axial impellers. Singh et al. (2011) compared the performance of the family of k- $\omega$ SST models with the Standard $\kappa-\varepsilon$ model using a Rushton turbine to induce turbulent flow. The domain was built with hexahedral elements and considering the blades as zero thickness walls. Important over-predictions in the peaks of the total TKE and deviations in the dissipation profiles were reported for a grid composed of hexahedral cells. More recently, Lane (2017) studied the flow parameters of a A310 hydrofoil comparing the k- $\omega$ SST model with the Standard $\kappa-\varepsilon$ model and detached eddy simulation (DES). A superiority of the $k-\omega$ SST was found in comparison to the Standard $\kappa-\varepsilon$ model predictions for a hybrid grid of about 3 million cells. The last two works disregarded the RNG and realizable models in their comparisons. Further, they were based on transient simulations which demand a considerable amount of computational resources. As a general conclusion, the capabilities are recognized of the RANS based models to reproduce fairly well the radial and axial velocities along the agitated tank, even for relatively coarse grids. However, underestimated values especially in the anisotropic regions (near the impeller), are expected for both, TKE and $\varepsilon$. The last two parameters are important in the design of agitated tank reactors as they are related to impeller efficiency, heat transfer, mixing and chemical reactions. From a computational fluid dynamics (CFD) perspective, most of the works which have compared the RANS based models have used a small number of cells, i.e., grids smaller than 600000 elements. Considering the relation between cell number and the turbulent parameters, new evaluations must be performed with higher cell numbers, based on the actual processing capabilities. Moreover, most of the simulations have been carried out using hexahedral cells, which are not suitable to map complex domains or those composed with accessories, and with impeller blades modeled as surfaces with zero thickness (zero thickness walls), which is an unrealistic simplification (Rutherford et al., 1996). As an alternative to map complex geometries, several works have implemented tetrahedral cells, i.e., domains with accessories such as a rotating ring electrode, for metal polluted water treatment (Martinez-Delgadillo et al., 2012), to analyze the flow patterns of a Max-Blend type impeller (Devals et al., 2008), among others. However, there is a lack of information about the performance of the different turbulence models in this kind of cell discretization under the same framework, for the flow induced by a PBT. Furthermore, to the best of the authors' knowledge, another type of non-structured meshing scheme such as the Cartesian CC method, which is also useful to grid complex domains (Kirkpatrick et al., 2003; Tucker and Pan, 2000), has not been examined yet in agitated tank modeling. Based on the above, the main objective of this work is to assess the performance of the RANS turbulence models (Standard $\kappa-\varepsilon, \mathrm{RNG}$, Realizable, k- $\omega, \mathrm{RSM}$ ) and the MRF approach to describe the flow patterns in agitated tanks by PBT means of applying either tetrahedral or CC grids, considering the blade thickness effect. Additional enhancements of classic models such as the inclusion of the swirl number " $\alpha$ " in the RNG model and the k- $\omega$ Shear Stress Transport (SST) are also investigated in both meshing schemes In order to validate the predictions, the maps of velocities, TKE, and $\varepsilon$ will be obtained through 2D-PIV, and the dissipated power in the whole tank will be obtained from torque measurements. The assessment presented in this work has the purpose of being a guideline for the selection of the most appropriate RANS model under the MRF approach, when the use of unstructured grids is unavoidable, and practical simulation times are needed (as in the engineering field). For illustrative purposes and in order to evaluate the influence of the temporal term in the solution, the most successful turbulence model and grid scheme (realizable in a domain composed of tetrahedral cells) was solved using the Sliding Mesh approach. The importance of this work relies on the fact that the prediction capabilities of the RANS based models have not been evaluated in unstructured domains under the same comparative basis. Considering that, in the modeling of complex agitated tank reactors, parameters such as bubble size distributions and other mixing features 
rely on the TKE or $\varepsilon$, the amount of deviation must be analyzed, especially for cases when unstructured grids are needed. Further, the $\mathrm{CC}$ meshing scheme, which is powerful to map complex domains, is included in the assessment of the flow parameters, which has not been evaluated in an agitated tank before.

\section{MATERIALS AND METHODS}

\section{STR geometry and operating conditions}

The experimental array, shown in Fig. 1, consisted of an acrylic tank with inner diameter $\mathrm{T}=250 \mathrm{~mm}$. The PBT impeller was composed of 4 blades rotated at $45^{\circ}$, with diameter $\mathrm{D}=\mathrm{T} / 3 \mathrm{~mm}$, a blade vertical projection $\mathrm{w}=14.3 \mathrm{~mm}$ and thickness of $1.5 \mathrm{~mm}$. Four equally spaced baffles with a width of T/10 and a thickness of $3.5 \mathrm{~mm}$ were arranged along the internal wall of the tank. Water was used as the working fluid and the liquid height was $\mathrm{H}=\mathrm{T}$, with a PBT bottom clearance of $\mathrm{C}=\mathrm{T} / 3$, in order to induce a single lateral loop flow (Mao et al., 1997).

To reduce refractive index effects on the measurements, the tank was placed inside a cubic tank filled with water at the same level. The angular velocity was set as $\mathrm{N}=8.33 \mathrm{~s}^{-1}(500 \mathrm{rpm})$; in such conditions the Reynolds number was calculated as Re $=\rho \mathrm{ND}^{2} / \mu \approx 52000$, indicating that fully turbulent flow was achieved. Water density $(\rho)$ of $998.2 \mathrm{~kg} / \mathrm{m}^{3}$ and a dynamic viscosity $(\mu)$ of $0.001003 \mathrm{~N} . \mathrm{s} / \mathrm{m}^{2}$ were taken in the calculation of all flow variables.

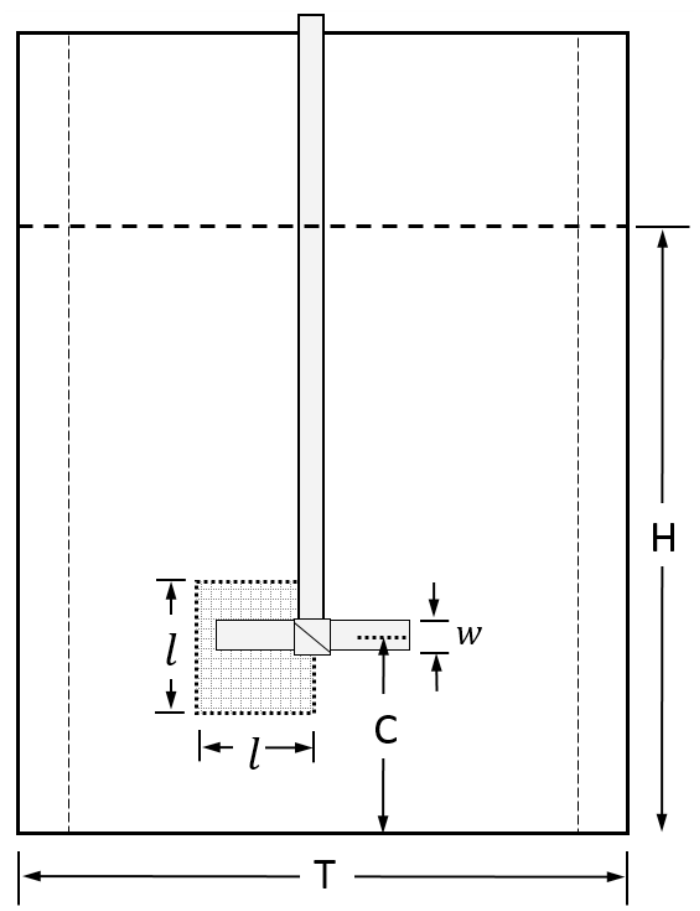

Figure 1. Geometrical representation of the STR, where $\mathrm{C}$ is the PBT bottom clearance, $w$ is the blade vertical projection, $\mathrm{T}$ is the tank inner diameter and $\mathrm{H}$ is the water height level.
Experimental apparatus (PIV and torque measurements)

A two-dimensional PIV system (TSI Incorporated) was used to acquire the flow field measurements inside the STR. The system incorporates a double-pulse $\mathrm{Nd}$ :YAG laser that generates a beam of $75 \mathrm{~mJ}$ per pulse, with a wavelength of $532 \mathrm{~nm}$ (green light spectrum). An optical array transforms the round laser beam into a light sheet approximately $1 \mathrm{~mm}$ thick, illuminating the plane of interest. Two sequential images were taken with a CCD camera with $2360 \times 1776$ pixels, with a minimum frame straddling time of $195 \mathrm{~ns}$, and a capture rate of 14 frames/s. A shaft encoder adapted to the circuit produces a trigger signal which assured that all images were taken at the moment when the blade and the laser sheet are at $0^{\circ}$. Hollow glass spheres coated with silver with diameters ranging from $8 \mu \mathrm{m}$ to $12 \mu \mathrm{m}$ and densities from $1015 \mathrm{~kg} / \mathrm{m}^{3}$ to $1030 \mathrm{~kg} / \mathrm{m}^{3}$ were used as tracer particles. The camera-laser array configuration is shown in Fig. 2.

The time difference between the image pairs was $100 \mu \mathrm{s}$. Employing a spatial resolution of $40 \mu \mathrm{m} / \mathrm{px}$, the zone of interest covered a rectangle of $94 \mathrm{~mm} \mathrm{x}$ $70 \mathrm{~mm}$, with a vector displacement of $\approx 0.64 \mathrm{~mm}$. A total of 800 images were processed using the Insight 4G software with the Nyquist recursive grid algorithm, resulting in 400 instantaneous velocity maps. The statistical convergence was assessed by comparing the differences in the mean and RMS velocities between 300 and 400 image pairs, being less than $3.5 \%$. Further, the mean values of the fluctuating velocities were verified to be zero. The torque was measured with a torque meter connected to the impeller shaft with a maximum load capacity of $1.41 \mathrm{~N} . \mathrm{m}$, and temperature control $\left(20^{\circ} \mathrm{C}\right.$ to $\left.75^{\circ} \mathrm{C}\right)$. The resultant value of torque was the mean value of 900 measurements obtained at regular intervals of $0.02 \mathrm{~s}$.

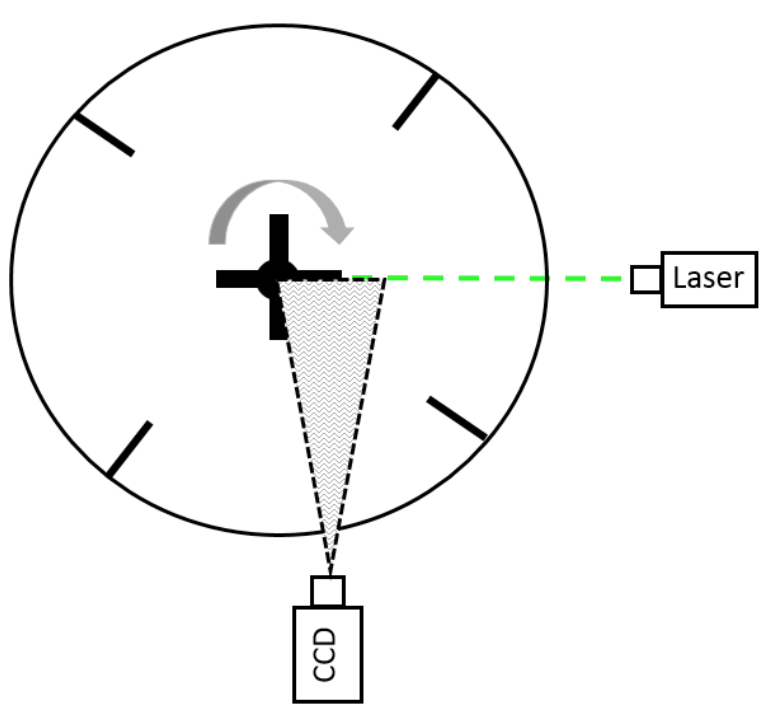

Figure 2. CCD and Laser array configuration used in the PIV measurements. 


\section{Measured turbulence kinetic energy}

As the PIV technique does not provide information about the third velocity component, the pseudoisotropic assumption of the turbulence is made, and the TKE content is calculated as a function of the two measured fluctuating velocities as shown in eq. (1).

$\mathrm{k}=\frac{3}{4}\left(\overline{\mathrm{u}^{\prime 2}}+\overline{\mathrm{v}^{\prime 2}}\right)$

This relation was addressed by Khan et al. (2006) and negligible deviations between 2D and 3D PIV maps were found for both magnitudes and locations. For that reason, it will be used in this research.

\section{Measurements of the turbulence dissipation rate}

From the experimental point of view, one of the most important challenges in the analysis of STRs is the estimation of $\varepsilon$, which relies on the measurement of the three spatial fluctuating velocities and their corresponding spatial derivatives and cross terms (12 terms). In this sense, from the 2 fluctuating velocity components measured by the 2D PIV technique, just 5 terms could be obtained. In order to estimate the contribution of the non-measured fluctuating velocity, the turbulence is considered as non-homogeneous but statistically isotropic, and is defined by eq. (2) (Sharp and Adrian, 2001).

$\varepsilon_{\mathrm{DE}}=v\left(2 \overline{\left(\frac{\partial \mathrm{u}^{\prime}}{\partial \mathrm{x}}\right)^{2}}+2 \overline{\left(\frac{\partial \mathrm{v}^{\prime}}{\partial \mathrm{y}}\right)^{2}}+3 \overline{\left(\frac{\partial \mathrm{v}^{\prime}}{\partial \mathrm{x}}\right)^{2}}+3 \overline{\left(\frac{\partial \mathrm{u}^{\prime}}{\partial \mathrm{y}}\right)^{2}}+2 \overline{\frac{\partial \mathrm{u}^{\prime}}{\partial \mathrm{y}} \frac{\partial \mathrm{v}^{\prime}}{\partial \mathrm{x}}}\right)$

This is known as the "direct evaluation" (DE) method, and gives a good approximation when the spatial resolution is around the Kolmogorov length scale

$\lambda_{\mathrm{K}}=\left(\frac{\mathrm{v}^{3}}{\bar{\varepsilon}_{\mathrm{T}}}\right)^{1 / 4}$.

In practice this is difficult to obtain as the focusing and calibration procedures get complicated, or the overall measured area is no longer significant to depict the flow patterns. For example, Saarenrinne et al. (2001) reported that, with a spatial resolution of $9 \lambda_{\mathrm{K}}$, just the $65 \%$ of the true dissipation rate could be obtained. From the dissipated power from the torque $\varepsilon_{\mathrm{T}}=0.215$ $\mathrm{W} / \mathrm{kg}$, and $\lambda_{\mathrm{K}} \approx 46 \mu \mathrm{m}$, and the spatial resolution of the PIV, $\Delta \approx 28 \lambda_{\mathrm{K}}$. Therefore, important sub-predictions of $\varepsilon$ are expected if this method is applied. An interesting alternative to compensate $\varepsilon$ in high spatial resolution measurements is the Large Eddy approach (Sheng et al., 2000). In this method, the contribution of the scales smaller than the interrogation window is modeled by a SGS model, similarly to the LES model of CFD (Sagaut, 2005). From the 2D PIV measurements, the dissipation rate from the large eddy approach $\varepsilon_{\mathrm{SGS}}$ is defined by eq. (3) (Khan, 2005).

$$
\varepsilon_{\mathrm{SGS}}=\left(\mathrm{C}_{\mathrm{s}} \Delta\right)^{2}\left(4 \overline{\left(\frac{\partial \mathrm{u}^{\prime}}{\partial \mathrm{x}}\right)^{2}}+4 \overline{\left(\frac{\partial \mathrm{v}^{\prime}}{\partial \mathrm{y}}\right)^{2}}+2 \overline{\left(\frac{\partial \mathrm{u}^{\prime}}{\partial \mathrm{y}}\right)^{2}}+2 \overline{\left(\frac{\partial \mathrm{v}^{\prime}}{\partial \mathrm{x}}\right)^{2}}\right)^{3 / 2}
$$

In this equation, the fluctuating derivative terms are affected by $\Delta$ and the Smagorinsky constant $\mathrm{C}_{\mathrm{s}}$. According to Meyers and Sagaut (2006), $\mathrm{C}_{\mathrm{s}}$ must be adjusted depending on the ratio $\Delta / \lambda_{K}$, which from our experiments was $\approx 28$, resulting in a $\mathrm{C}_{\mathrm{s}}$ value of 0.16 . In the discussion of the results, the Large Eddy approach will be used as the direct evaluation method and is expected to severely under-predict. Also, for comparison purposes, the $\varepsilon$ maps will be normalized by the tank-averaged specific dissipation rate as $\varepsilon^{*}=$ $\varepsilon / \varepsilon_{\mathrm{T}}$

\section{CFD MODELLING}

\section{Model configuration and boundary conditions}

A tridimensional replica of the STR fluid domain described in the previous section was built and solved in segregated form with FLUENT V.13. Two zones were defined inside the STR, a rotational one near the impeller (Zone 1) and a stationary one in the rest of the domain (Zone 2), as required for the MRF and SM approaches, by using the ANSYSMeshing tool. Zone 1, which contained the impeller walls, was composed of a cylindrical volume with diameter $1.4 \mathrm{D}$ and height $2.6 \mathrm{w}$, the gap between the upper blade wall and the upper cylinder wall being 0.8 w. The average skewness for all tetrahedral and CC grids were approximately 0.2 and 0.05 respectively, with their maximum skewness below 0.8. The latter values accomplish the requirements of maximum skewness below 0.95 and average values below 0.3 for tetrahedral elements stated in the Fluent User's Manual (Ansys, 2009). For the CC grids, it is noticeable that, as the vertex angles of the elements are almost $90^{\circ}$, cells with very low skewness values are possible. The velocity-pressure coupling was performed with the SIMPLE algorithm, which has been successfully tested in stirred tanks (Jaworski et al., 1997; Karimi et al., 2012). The convective terms of the momentum, " $k$ " and " $\varepsilon$ " equations were discretized adopting the second order upwind scheme, as higher order schemes such as QUICK (quadratic upwind interpolation for convective kinematics) do not improve substantially the predictions (Coroneo et al., 2011). For the pressure interpolation, the second order scheme was used. The convergence criterion of the solution was fixed to $1 \times 10^{-5}$ for the residuals of all solved equations, and a 
constant value of torque and total content of dissipated power were also verified. Such convergence level is higher than the $10^{-3}$ of Jaworski et al. (1997) or the $10^{-4}$ used by Delafosse et al. (2008). At all walls, the non-slip condition with standard log-law function is imposed. The free surface was treated as symmetry (zero shear stress wall) and the constants of all models were set to the default values of FLUENT. For the SM simulation, the second order implicit scheme was applied, each time step being $\Delta \mathrm{t}=3.33 \times 10^{-4} \mathrm{~s}\left(1^{0}\right.$ of blade rotation) with 20 subiterations. This time resolution is lower than the Kolmogorov time scale $\sqrt{V}_{\mathrm{V}} / \varepsilon_{\mathrm{T}} \approx 0.0022 \mathrm{~s}$ obtained from the experimental dissipated power. The statistics for velocities and turbulent parameters were obtained from 30 impeller revolutions, exceeding the 20 revolutions reported by $\mathrm{Ng}$ et al. (1998) in the modeling of the turbulent flow induced by a Rushton turbine.

\section{Grid independence analysis}

Overall description of the evaluated grids

As shown in Table 2, four grids were constructed for each method, ranging from 0.7 million cells (CC $0.7 \mathrm{M}$ ) to 6.2 million cells (CC 6.2M) for the $\mathrm{CC}$, while for the tetrahedral the grid sizes were from $0.9 \mathrm{M}$ to 6.1 M. All grids were evaluated using the Realizable model, that in prior simulations performed well with both types of cell elements. Starting from the coarse grids, cell numbers were increased systematically by a factor close to two, in order to assure different nodal configurations.

In the rotational zone (Zone 1), the cell elements were clustered especially near the PBT walls in order to capture the main flow gradients induced by the axial swirl motion. For example, for the $\mathrm{CC}$ grids, the $\mathrm{CC} 0.7 \mathrm{M}$ model has $16 \%$ of the cells in the rotating region while for the $\mathrm{CC} 6.2 \mathrm{M}, 45 \%$. A maximum grid spacing of $2 \mathrm{~mm}$ was applied in the impeller blade for the coarse grids, while for the finer grids the spacing was $0.225 \mathrm{~mm}$. All grids took about 11000 iterations to converge. As expected, the time consumed by the iteration increased with refinement. Also, a slight decrease of simulation time was achieved by using tetrahedral cells. That is noticeable by comparing the
$3.4 \mathrm{~s}$ versus the $4.5 \mathrm{~s}$ per iteration between the $\mathrm{T} 3.3$ $\mathrm{M}$ and $\mathrm{CC} 3.6 \mathrm{M}$, and the $6.7 \mathrm{~s}$ and $7.5 \mathrm{~s}$ between the finest grids. For the SM model, each sub-iteration took about $1.5 \mathrm{~min}$ and the statistical results were obtained after approximately 5 days of continuous simulation. The simulations were performed using a Dell $\AA$ Workstation with 2 processors Xeon E5-2620 and 64 GB of RAM.

Cell number influence on the pumping and power number

The pumping number which characterizes the pumping capabilities of different type of impellers is defined by eq. (4). A value of $\mathrm{N}_{\mathrm{q}}=0.82$ was obtained from the mean axial velocity profile extracted from the PIV, at a line $3 \mathrm{~mm}$ below the impeller, according to

$$
\mathrm{Q}=\rho \int_{0}^{\mathrm{R}} 2 \pi \mathrm{V}_{\mathrm{a}} \mathrm{rdr}
$$

This value presented fair agreement with the $\mathrm{N}_{\mathrm{q}}=$ 0.79 reported by Weetman and Oldshue (1988). In order to numerically investigate this parameter, Fig. 3 shows the $\mathrm{N}_{\mathrm{q}}$ values as a function of cell sizes for both meshing schemes. For all grids, $\mathrm{N}_{\mathrm{q}}$ values were practically independent of the cell number, excepting the $\mathrm{CC}$ 6.2M grid, which resulted in about a $9 \%$ overestimation.

$$
\mathrm{N}_{\mathrm{q}}=\frac{\mathrm{Q}}{\rho \mathrm{ND}^{3}}
$$

The power number $\mathrm{N}_{\mathrm{p}}$ defined by eq. (5) is another important non-dimensional parameter which is related to the dissipated power in the entire vessel. It was calculated from the shaft power $(\mathrm{M}=2 \pi \mathrm{NT})$ derived from torque measurements, using $\mathrm{T} \approx 0.0441$ N.m. The resulting value was estimated as $\mathrm{N}_{\mathrm{p}}=1.26$ which was in accordance with $\mathrm{N}_{\mathrm{p}}=1.27$, reported by Chapple et al. (2002).

$$
\mathrm{N}_{\mathrm{p}}=\frac{\mathrm{P}}{\rho \mathrm{N}^{3} \mathrm{D}^{5}}
$$

Table 2. Sizes of the grids evaluated in the independence analysis.

\begin{tabular}{ccccccccc}
\hline Grid & $\begin{array}{c}\text { Zone 1 } \\
\mathbf{1 0}^{\mathbf{6}}\end{array}$ & $\begin{array}{c}\text { Zone 2 } \\
\times \mathbf{1 0}^{\mathbf{6}}\end{array}$ & $\begin{array}{c}\text { Total } \\
\text { Cells } \\
\times \mathbf{1 0}^{\mathbf{6}}\end{array}$ & $\begin{array}{c}\text { MRF-Zone 1 } \\
\mathbf{\varepsilon} \\
\mathbf{( W / k g )}\end{array}$ & $\begin{array}{c}\text { Zone 2 } \\
\boldsymbol{\varepsilon} \\
(\mathbf{W} / \mathbf{k g})\end{array}$ & $\begin{array}{c}\text { Total } \\
\mathbf{\varepsilon} \\
(\mathbf{W} / \mathbf{k g})\end{array}$ & $\begin{array}{c}\text { Blade cell } \\
\text { spacing } \\
(\mathbf{m m})\end{array}$ & $\begin{array}{c}\text { Iteration } \\
\text { time } \\
(\mathbf{s})\end{array}$ \\
\hline CC 0.7 M & 0.11 & 0.57 & 0.68 & $0.044(33 \%)$ & 0.090 & 0.134 & 1.5 & 1 \\
CC 1.1 M & 0.21 & 0.90 & 1.11 & $0.048(32 \%)$ & 0.100 & 0.149 & 0.5 & 1.2 \\
CC 3.6 M & 1.07 & 2.50 & 3.57 & $0.115(49 \%)$ & 0.122 & 0.237 & 0.25 & 4.5 \\
CC 6.2 M & 2.77 & 3.42 & 6.19 & $0.099(48 \%)$ & 0.110 & 0.208 & 0.225 & 7.5 \\
T 0.9 M & 0.27 & 0.62 & 0.89 & $0.053(38 \%)$ & 0.085 & 0.138 & 2.000 & 1 \\
T 1.7 M & 0.64 & 1.02 & 1.66 & $0.058(37 \%)$ & 0.099 & 0.156 & 1.000 & 1.7 \\
T 3.3 M & 1.38 & 1.88 & 3.26 & $0.066(40 \%)$ & 0.100 & 0.166 & 0.375 & 3.4 \\
T 6.1 M & 1.42 & 4.71 & 6.13 & $0.073(42 \%)$ & 0.100 & 0.173 & 0.225 & 6.7 \\
\hline
\end{tabular}




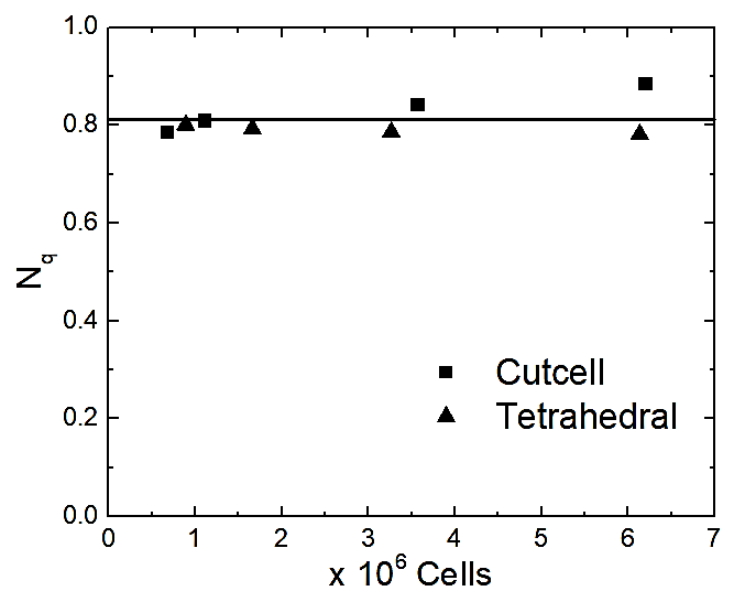

Figure 3. Pumping number as function of cell number for the two grid approaches.

From the simulations, the power number could be estimated from a torque monitor defined at the impeller walls, or by the volume integral of the total amount of dissipated power $\varepsilon$ predicted by the turbulence model, according to eq. (6) (Ge et al., 2014).

$\mathrm{N}_{\mathrm{p}-\varepsilon}=\frac{\int_{0}^{\mathrm{T} / 2} \int_{0}^{\mathrm{H}} \int_{0}^{2 \pi} \rho \varepsilon d \operatorname{drd} \mathrm{d} \theta}{\rho \mathrm{N}^{3} \mathrm{D}^{5}}$

The predicted power numbers from torque and derived from the total content of dissipated power as a function of cell number are shown in Fig. 4. Similarly to $\mathrm{N}_{q}$, the $\mathrm{N}_{\mathrm{p}}$ obtained from the numerical torque presented reasonable agreement with the experimental value (horizontal black line), independently of the grid refinement. However, in the case of $\mathrm{N}_{\mathrm{p}-\varepsilon}$ the two meshing techniques showed different tendencies. For the $\mathrm{CC}$ grids, $\mathrm{N}_{\mathrm{p}-\varepsilon}$ increased importantly as a function of the cell number for the two first consecutive

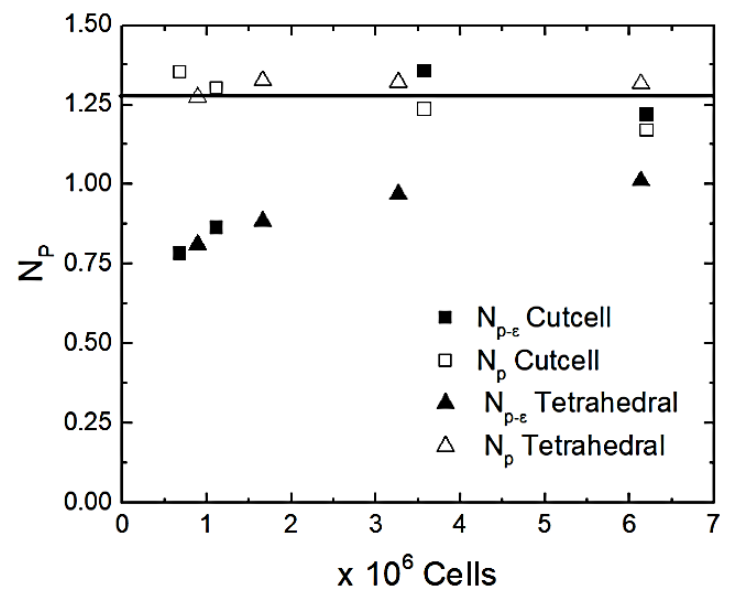

Figure 4. Power number derived from torque and total dissipated power as a function of cell number for the two grid approaches. Horizontal line refers to $\mathrm{N}_{\mathrm{p}}$ from the torque measurement. refinements, until reaching a 1.36 value. This value was overestimated by $7 \%$ in comparison with the measured value. However, this effect did not remain for the CC $6.2 \mathrm{M}$ grid, and the value decreased to $\mathrm{N}_{\mathrm{p}-\varepsilon}$ $\approx 1.2$, that is, underestimated by $5 \%$.

For the tetrahedral grids, although all refinements increased $\mathrm{N}_{\mathrm{p}} \varepsilon_{\varepsilon}$, all values were in general underpredicted. For the coarse grid (T $0.9 \mathrm{M})$, the difference between the experimental and the predicted values was $30 \%$, while for the fine grid, the difference was about $20 \%$. It is noticeable that, for the T $3.3 \mathrm{M}$ and the $\mathrm{T} 6.1 \mathrm{M}$ models, the predictions of $\mathrm{N}_{\mathrm{p}-\varepsilon}$ were quite similar, but the finer grid took much longer to converge; consequently, no benefit was found in this parameter for the last refinement. For both algorithms, the $\mathrm{N}_{\mathrm{p}-\varepsilon}$ was strongly dependent on the grid sizes for the grids smaller than 3 million elements, and further refinements did not deliver important increases, suggesting a non-linear relation between the integral dissipation and cell number, and the existence of an optimum mesh size. A similar trend between the increase of cell number and the improvement of the predicted $\mathrm{N}_{\mathrm{p}-\varepsilon}$ was pointed out by Coroneo et al. (2011). According to them, the increase of the cell number is related to an increase in the turbulence levels of the domain, which is reflected in $\mathrm{N}_{\mathrm{p}-\varepsilon}$ predictions.

Profiles of TKE and $\varepsilon$ as function of the number of cells

To extend the assessment of the cell number influence on the main flow parameters which define the flow patterns in the agitated tank, Fig. 5 shows the non-dimensional profiles of production and dissipation rates obtained from a radial line located $3 \mathrm{~mm}$ below the impeller, for the two types of unstructured grids. The location of this line was chosen considering that it is immersed in a zone where high gradients take place. For the CC grids, shown in Fig. 5a and 5b, no important deviations were present between the CC $3.6 \mathrm{M}$ and $\mathrm{CC} 6.2 \mathrm{M}$, especially for $\varepsilon$. In a similar way, for the tetrahedral meshing shown in Fig $5 \mathrm{c}$ and $5 \mathrm{~d}$, no significant differences were found between the $\mathrm{T} 1.7 \mathrm{M}$, the $\mathrm{T} 3.3 \mathrm{M}$ and $\mathrm{T} 6.1 \mathrm{M}$ for both turbulent parameters. As a summary, for the case of the CC grids with $\geq 3.6 \mathrm{M}$ elements, turbulent profiles did not present important changes, and integral parameters such as $\mathrm{N}_{\mathrm{g}}, \mathrm{N}_{\mathrm{p}}$ and $\mathrm{N}_{\mathrm{p}-\varepsilon}$ were fairly predicted.

According to this, and considering the time consumption of the finer grid, CC $3.6 \mathrm{M}$ was chosen to perform the final runs for the remaining turbulence models. For the tetrahedral meshing scheme, although most of the parameters were independent from the $\mathrm{T} 1.7 \mathrm{M}$ grid, on the $\mathrm{T} 3.3 \mathrm{M}$ grid was chosen for the final runs, in order to preserve uniformity in the cell number of both meshing approaches. Finally, the Grid Convergence Index (GCI) (Roache, 1994), which is a conservative parameter that points out the asymptotic 

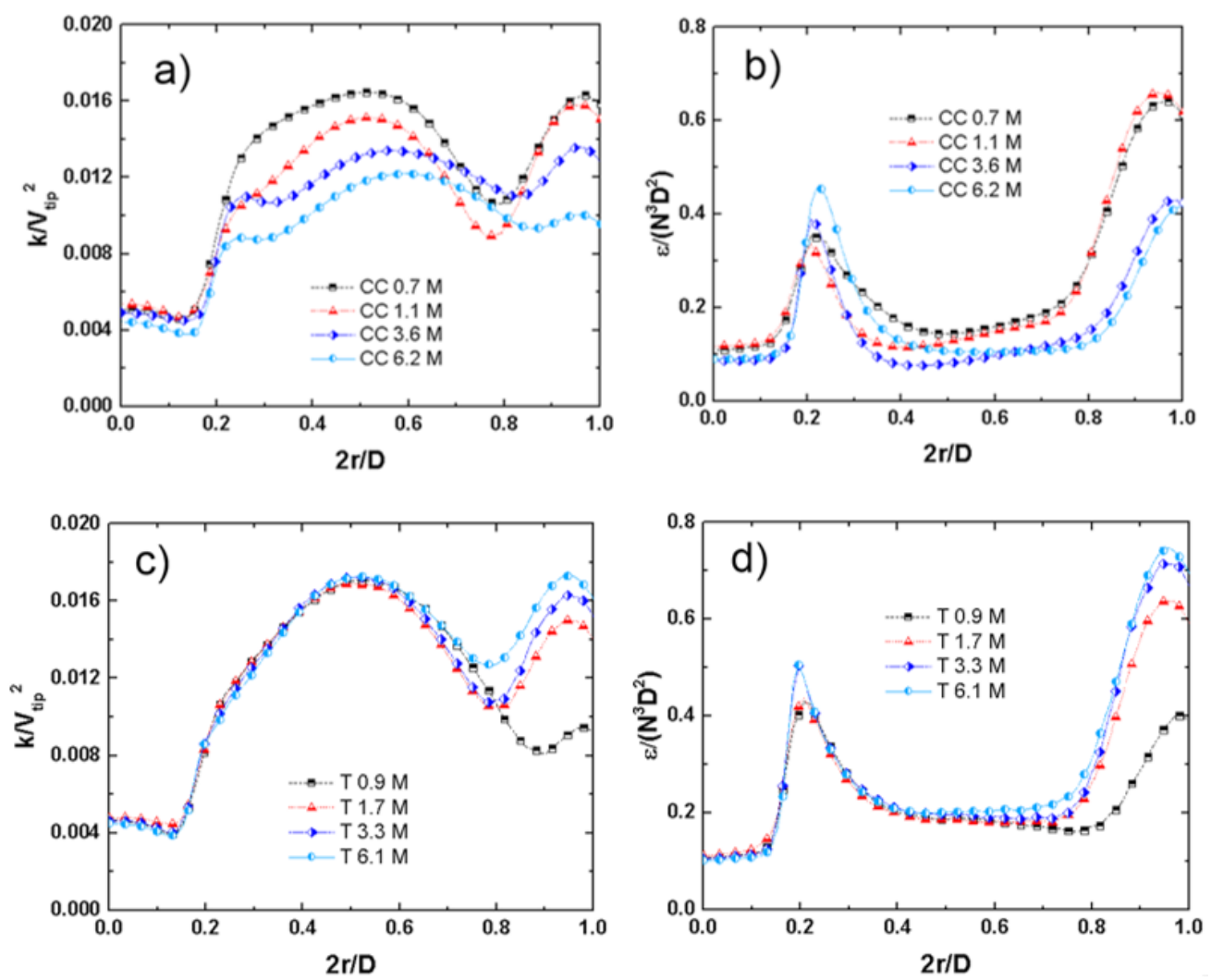

Figure 5. Non-dimensional TKE and $\varepsilon$ profiles for the tetrahedral $(\mathrm{T})$ and $\mathrm{CC}$ grids. Note the similar sizes between cell types and that the number of elements was sequentially doubled.
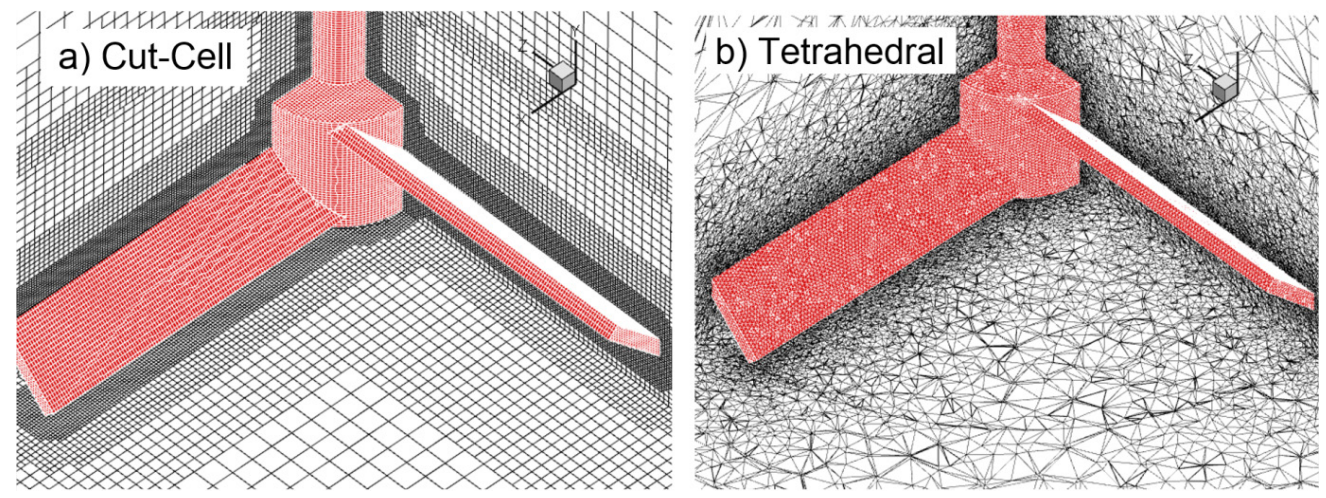

Figure 6. Grids implemented for the final simulations: a) Grid composed of 3.6 million cells for the CC method b) Tetrahedral grid composed of 3.3 million cells.

behavior in flow solutions, was $5 \%$ for $\mathrm{N}_{\mathrm{p}-\varepsilon}$ and the T $3.3 \mathrm{M}$ model. Figs. $6 \mathrm{a}$ and $6 \mathrm{~b}$ show the nodal configuration of the two modeling approaches in a region near the PBT impeller. For both final grids (CC and tetrahedral), 4 elements were disposed in the blade thickness, 40 along the blade width and approximately 90 cells covered the blade length.

\section{RESULTS}

\section{Location of the axial and radial lines used to plot the profiles}

In order to evaluate the profiles of the mean velocities and turbulent parameters, four lines which enveloped the PBT blade were constructed. As shown in Fig. 7, the discharge and radial lines " $1_{\mathrm{d} 1}$ " and " $\mathrm{l}_{\mathrm{r} 1}$ " were located using an offset of $3 \mathrm{~mm}$ from the PBT wall projection on the " $x-y$ " plane which slices the mid-blade at $0^{\circ}$. The radial and axial lines " $\mathrm{d}_{\mathrm{d} 2}$ " and " $\mathrm{l}_{\mathrm{r} 2}$ " were obtained by applying an offset of $10 \mathrm{~mm}$ from the " $l_{\mathrm{d} 1}$ " and " $\mathrm{r}_{\mathrm{r} 1}$ " lines.

\section{The power and pumping numbers}

The CFD predictions of the pumping and power numbers (from torque monitor $\mathrm{N}_{\mathrm{p}}$ and from dissipated power $\mathrm{N}_{\mathrm{p}-\varepsilon}$ ) for the $\mathrm{CC}$ and tetrahedral grids are shown in Figs. 8a and 8b. From now on, STD stands for the Standard $\kappa-\varepsilon$ model, RNG $\alpha=0.07$ refers to the RNG 


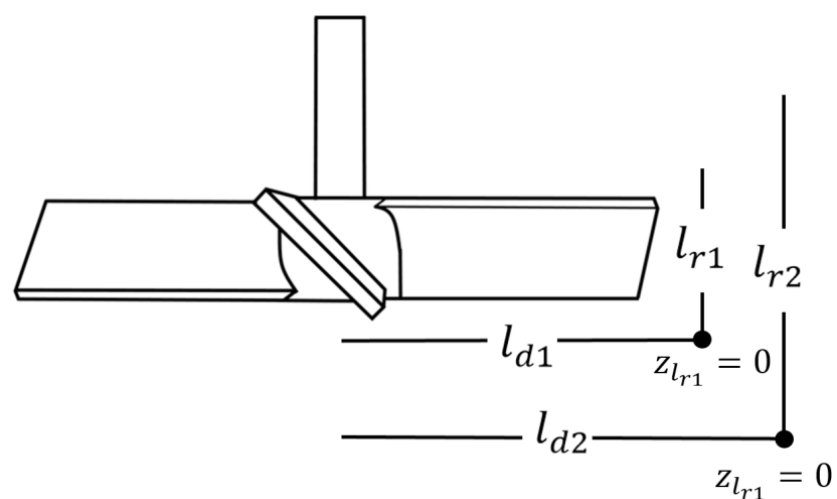

Figure 7. Axial and radial discharge lines used to compare the velocity profiles for both unstructured grids.

model with a Swirl Number of 0.07, REA stands for the Realizable, $k-\omega$ SST refers to the k- $\omega$-Shear Stress Transport model and RSM to the Reynolds Stress transport model. For the CC scheme, all models predicted fairly well the experimental pumping number of 0.82 . For the Tetrahedral grids, most of the models delivered fair values except for RNG $\alpha=0.07$ and RSM, which underpredicted the value by $24 \%$ and $22 \%$, respectively. Comparing Figures $8 \mathrm{a}$ and $8 \mathrm{~b}$, the $\mathrm{CC}$ grids showed a slight superiority for $\mathrm{N}_{\mathrm{q}}$ predictions in comparison to the tetrahedral approach for all turbulence models. For the $\mathrm{N}_{\mathrm{p}}$ using Cartesian grids, the STD and REA models presented good agreement with the measured value, as predictions deviated by less than $4 \%$. The $\mathrm{k}-\omega$ value was underpredicted by $10 \%$, while the RNG and RSM models were about $15 \%$ and $20 \%$ below the experimental value. The prediction of this parameter delivered good results by using tetrahedral grids for all models, except the RSM which deviated approximately $10 \%$. Comparing both meshing approaches, the tetrahedral grids performed better than the $\mathrm{CC}$ approach for $\mathrm{N}_{\mathrm{p}}$ predictions.

For its significance in mixing and chemical reaction, the assessment of the power number derived from the

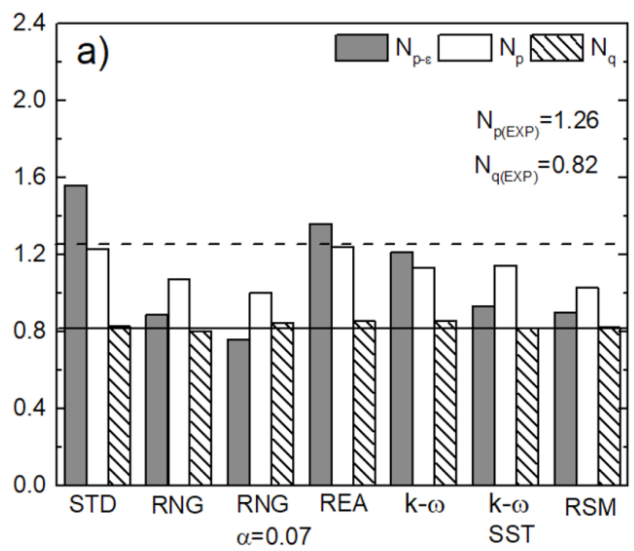

dissipated power is particularly important. For the CC grids, the STD model overestimated $\mathrm{N}_{\mathrm{p}-\varepsilon}$ by about 25 $\%$, and the RNG, RNG- $\alpha$, RSM and k- $\omega$ SST values were underpredicted between the minimum of $26 \%$ for the k- $\omega$ SST and the maximum of $40 \%$ obtained for the RNG- $\alpha$. Better agreement was found for the REA model that overestimated $\mathrm{N}_{\mathrm{p}-\varepsilon}$ by $10 \%$ and the $\mathrm{k}-\omega$ which underpredicted it by about $4 \%$. For the tetrahedral grids, as shown in Fig. 8b, most models significantly underpredicted $\mathrm{N}_{\mathrm{p}-\varepsilon}$ up to $50 \%$. In this case, the closer predictions were found for the STD model (16\% subestimated) and the REA model (23\% subestimated). Comparing both meshing approaches, more important subpredictions were present when tetrahedral grids were implemented. The RNG, RNG- $\alpha$ and RSM performed poorly for both mesh types, and the REA and k- $\omega$ applied to CC grids predicted fairly $\mathrm{N}_{\mathrm{p}-\varepsilon^{*}}$. As a summary, in order to present some hints about the superiority of a certain turbulence model or meshing approach, Table 3 shows an assessment of the model capabilities to predict the non-dimensional numbers on the same basis. The symbol " $\checkmark$ " is given if a variable presented less than a $10 \%$ deviation compared to the experimental value; otherwise, the prediction is considered failed and an " $\mathrm{x}$ " is marked. On this basis, and counting the total number of successes, the REA and k- $\omega$ models presented the best performance, followed by the STD and k- $\omega$ SST.

Table 3. Assessment of the different turbulence models and the two distinctive meshing algorithms.

\begin{tabular}{|c|c|c|c|c|c|c|}
\hline Algorithm & & $\mathrm{CC}$ & & & hed & \\
\hline Model & $\mathrm{N}_{\mathrm{p}-\varepsilon}$ & $\mathrm{N}_{\mathrm{p}}$ & $\mathrm{N}_{\mathrm{q}}$ & $\mathrm{N}_{\mathrm{p}-\varepsilon}$ & $\mathrm{N}_{\mathrm{p}}$ & $\mathrm{N}_{\mathrm{q}}$ \\
\hline STD & $\mathrm{X}$ & $\checkmark$ & $\checkmark$ & $\mathrm{X}$ & $\checkmark$ & $\checkmark$ \\
\hline RNG & $\mathrm{x}$ & $\mathrm{x}$ & $\checkmark$ & $\mathrm{x}$ & $\checkmark$ & $\checkmark$ \\
\hline RNG $\alpha=0.07$ & $\mathrm{x}$ & $\mathrm{x}$ & $\checkmark$ & $\mathrm{x}$ & $\checkmark$ & $\mathrm{x}$ \\
\hline REA & $\checkmark$ & $\checkmark$ & $\checkmark$ & $\mathrm{x}$ & $\checkmark$ & $\checkmark$ \\
\hline$k-\omega$ & $\checkmark$ & $\checkmark$ & $\checkmark$ & $\mathrm{x}$ & $\checkmark$ & $\checkmark$ \\
\hline$k-\omega$ SST & $\mathrm{x}$ & $\checkmark$ & $\checkmark$ & $\mathrm{x}$ & $\checkmark$ & $\checkmark$ \\
\hline RSM & $\mathrm{x}$ & $x$ & $\checkmark$ & $\mathrm{x}$ & $\checkmark$ & $\mathrm{X}$ \\
\hline
\end{tabular}

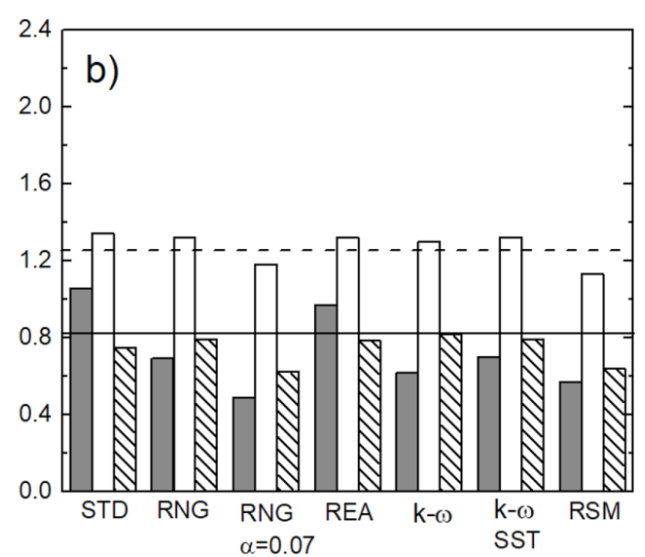

Figure 8. Assessment of the power (from torque monitor $\mathrm{N}_{\mathrm{p}}$ and from dissipated power $\mathrm{N}_{\mathrm{p}-\varepsilon}$ ) and pumping number $\left(\mathrm{N}_{\mathrm{q}}\right)$ obtained with the different turbulence models using a) CC grid and b) tetrahedral grid. The horizontal lines refer to experimental values. 
For the three parameters, no profit was derived from the implementation of the swirl factor $\alpha$ for the RNG model, nor for the k- $\omega$ model enhancements of the k- $\omega$ SST.

Profiles of velocities and turbulent parameters of further improvements of the RNG and $k-\omega$ models

In the previous section, it was shown that the models RNG $\alpha=0.07$ and $\mathrm{k}-\omega$ SST did not improved
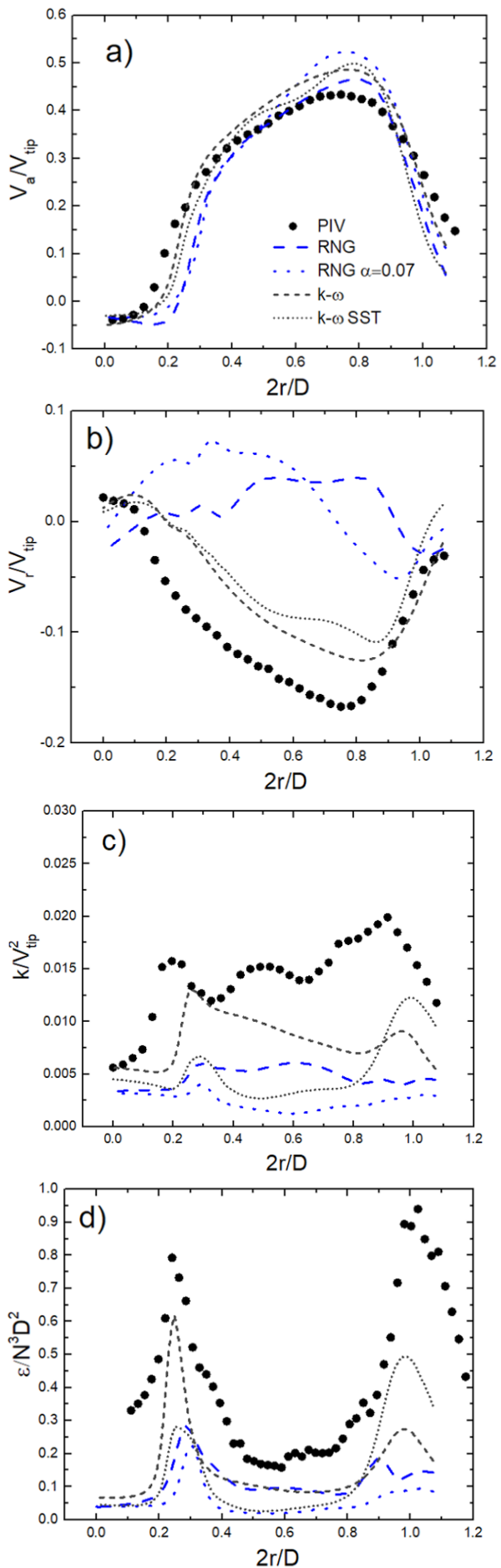

the predictions of the power and pumping numbers. In order to explore its local behavior in a high gradient region, Fig. 9 shows the non-dimensional profiles of axial and radial velocity, TKE and dissipation plotted along the line $1_{\mathrm{d} 1}$. Figs. 9 a-d refer to the profiles derived from the $\mathrm{CC}$ grid, while Figs. 9 e-h were obtained from the tetrahedral grid. In the case of the $\mathrm{CC}$ grid, although in general terms, the axial velocity
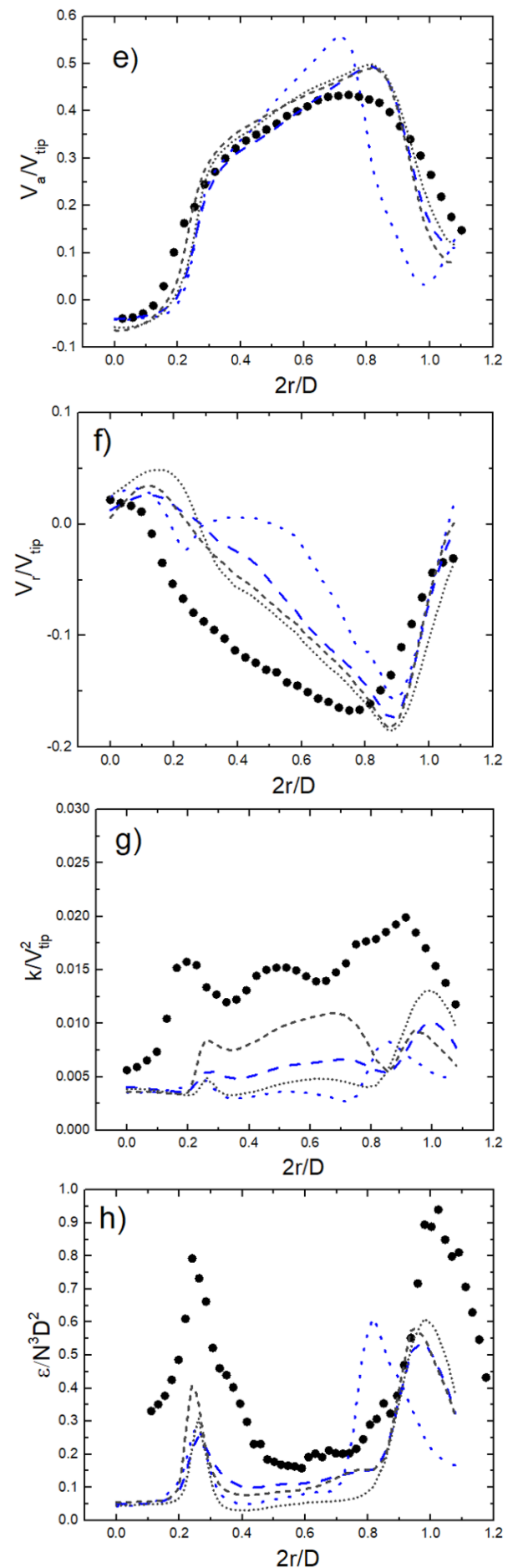

Figure 9. Assessment of the non-dimensional axial velocity, radial velocity, TKE and $\varepsilon$ profiles obtained with the RNG, RNG $\alpha=0.07, \mathrm{k}-\omega$ and $\mathrm{k}-\omega$ SST models using a) $-\mathrm{d}$ ) CC grid and e) $-\mathrm{h}$ ) tetrahedral grid. Black dots refer to experimental values from PIV. 
was reasonably predicted by the RNG $\alpha=0.07$ (not as good as the RNG model), while the radial velocity, TKE and dissipation rate were underpredicted. The same was observed for the tetrahedral approach (Figs. 9 e-h), although in this case, the axial velocity deviated, notably near the impeller tip, where higher gradients are present. For both meshing approaches, the inclusion of the swirl number caused a damping effect in the TKE and $\varepsilon$ predictions of the RNG model. The k- $\omega$ SST model practically does not influence the solutions of the $\mathrm{k}-\omega$ model regarding the axial velocities of both meshing approaches (Fig. 9a and Fig. 9e), and the radial velocities were slightly underpredicted, as shown in Figs. 9b and 9f. For the turbulent parameters, underestimations were also present when a comparison was made between the $\mathrm{k}-\omega$ and experimental data. As is shown, the RNG $\alpha=0.07$ and $k-\omega$ SST models caused underpredictions in the TKE and dissipation rate profiles, and in some cases, deviation in the mean velocities. Accordingly, in the following sections just the RNG and k- $\omega$ will be included in the analysis.

\section{Velocity profiles plotted along the axial and radial discharge lines}

The non-dimensional profiles of axial velocity at the four lines described in Figure 7 are shown in Figure 10. Here the letters a-d (left column of figures) will refer to the profiles extracted from the CC grid, whereas the right column (letters e-h) will refer to those profiles extracted from the tetrahedral grid. For simplicity, the same configuration was applied to Figs. 11-13. In the line $1_{\mathrm{d} 1}$ of Figs. 10a and 10e, all models regardless of the discretization scheme were able to capture the PIV parabolic axial velocity profile as a consequence of the PBT axial pumping, which is also related to the good $\mathrm{N}_{\mathrm{q}}$ predictions. Also, our PIV measurements presented excellent agreement with data of LDV of Chapple et al. (2012) shown in Fig. 10e. However, the RSM showed slightly underpredicted values for the $\mathrm{CC}$ mesh and deviated values for the tetrahedral grid near the blade tip. For the line $1_{\mathrm{d} 2}$, the PIV profile is stretched and it is directed mainly in the axial direction as the pumping is developed, presenting a maximum of $\mathrm{V}_{\mathrm{a}} / \mathrm{V}_{\text {tip }} \approx 0.5$ at $2 \mathrm{r} / \mathrm{D} \approx 0.7$. From the $\mathrm{CC}$ mesh, shown in Fig. $10 \mathrm{~b}$, the STD, REA and k- $\omega$ models presented fair agreement with PIV, and subestimated values were obtained for the RNG and RSM models. For the tetrahedral grid, all models presented acceptable agreement with the PIV results. In the axial line near the impeller tip $1_{r 1}$, the experimental values showed maximum axial velocity values of $\mathrm{V}_{\mathrm{a}} / \mathrm{V}_{\text {tip }} \approx 0.5$ in $\mathrm{z} / \mathrm{w}=0.1$ and a minimum $\mathrm{V}_{\mathrm{a}} / \mathrm{V}_{\text {tip }} \approx 0.5$ in $\mathrm{z} / \mathrm{w}=0.7$. The particular shape of the profile corresponds to a zone with high deformation, a consequence of the tip vortices formed in the PBT tips. All models except the RNG reproduced the PIV profile for the $\mathrm{CC}$ approach. When the tetrahedral grid was used, again, most of the turbulence models were able to reproduce the PIV profile. In this case, the RSM delivered the lower values. The experimental velocity profile in the line $1_{\mathrm{r} 2}$ was almost constant, and presented low axial velocity. This is expected as it is located outside the strong pumping region. In this location, when the Cartesian grid was used, the RANS models showed under-predicted values. For the tetrahedral grid, the RNG, REA and k- $\omega$ models presented fair agreement with the PIV values; however, underpredicted values were found for the STD and RSM models. The non-dimensional radial velocity profiles are shown in Fig. 11. For the radial line next to the impeller, $1_{\mathrm{d} 1}$, the experimental profile indicated a maximum $\mathrm{V}_{\mathrm{r}} / \mathrm{V}_{\text {tip }} \approx 0.2$ in $2 \mathrm{r} / \mathrm{D}=0.75$, indicating that the flow is slightly deflected outwards in the discharge region as consequence of the blade angle.

In this line, the REA model was able to reproduce the experimental profile, regardless of the meshing scheme. Although for the tetrahedral grid, the k- $\omega$ model delivered good predictions, it failed for the CC grid. The rest of the models delivered underpredicted values. For the line $1_{d 2}$ immersed in the middischarge region below the PBT, as the flow profile is dominated by the axial velocity components, the radial velocities are almost negligible as shown by the PIV profile. By using the CC grid, the STD, REA and $\mathrm{k}-\omega$ predictions followed fairly well the almost constant shape of the PIV profile, while the RNG and RSM models overestimated. For the tetrahedral grid shown in Fig. 11f, all models predicted fairly well the experimental (PIV) data with the exception of the RSM model, which presented overestimated values. The experimental values obtained for the $1_{\mathrm{r} 1}$ line near the impeller tip presented a curved parabolic profile with maximum value of $\mathrm{V}_{\mathrm{r}} / \mathrm{V}_{\text {tip }}=0.05$ at $\mathrm{z} / \mathrm{w}=$ 0.4 , followed by a transitional point where the radial velocity switched from positive to negative values in $\mathrm{z} / \mathrm{w}=0.6$ and a minimum of $\mathrm{V}_{\mathrm{r}} / \mathrm{V}_{\text {tip }}=0.12$ at about $\mathrm{z} / \mathrm{w}=1.0$. This sign change of the velocity is related to the existence of a recirculation region near the PBT tip, pointing out a strong swirl motion near the blade tips. Good agreement with the experimental results was present for the STD, REA and k- $\omega$ models. The RNG values were slightly shifted to the right, and those of the RSM presented overestimated values in the locations $\mathrm{z} / \mathrm{w}<0.6$. For the tetrahedral grid, the STD and the REA model, although slightly shifted to the right, presented acceptable agreement with the experimental data. The RNG, $\mathrm{k}-\omega$ and RSM profiles failed in their predictions as they were shifted and presented overestimated values. Finally, for the line $1_{\mathrm{r}}$, immersed in the lateral main recirculation loop, all models predicted fairly well the PIV constant profile with low velocities. However, an oscillatory response was found for the RNG model resolved in the CC grid. 

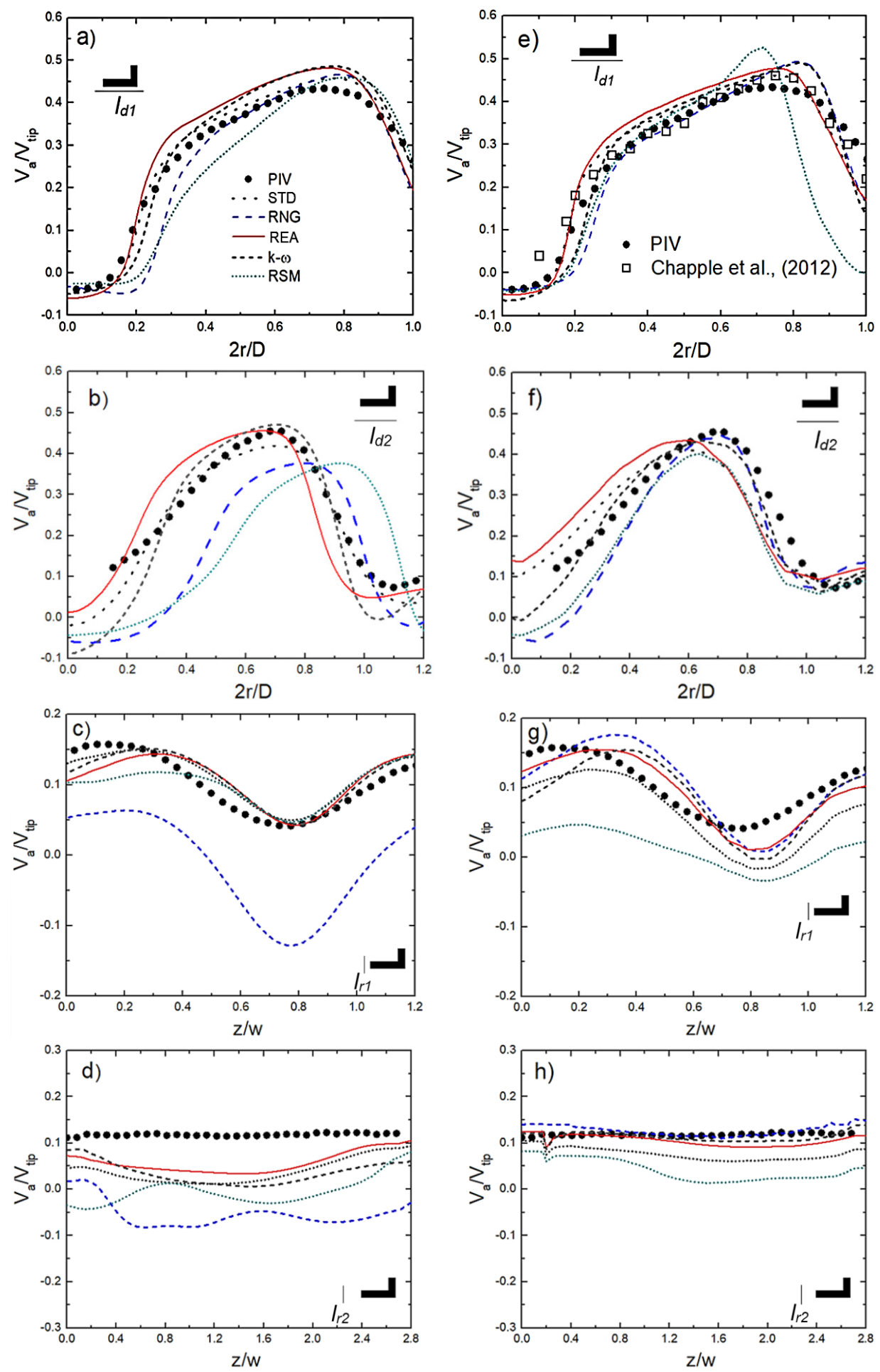

Figure 10. Assessment of the non-dimensional axial velocity profiles from different lines (shown in Fig. 7) obtained with the STD, RNG, REA, k- $\omega$ and RSM models using a) - d) CC grid and e) - h) Tetrahedral grid.

This peculiar profile is related with numerical issues present in the interphase .

\section{Profiles of TKE and $\varepsilon$}

Because the fluctuating velocities are related to turbulent mixing and dispersion, the TKE is one of the most important parameters in agitated tanks design. This parameter is also particularly sensitive to the impeller geometry and rotational velocity as it is developed mainly near the PBT walls and discharge region, where the bigger swirls which feed the energy cascade are formed (Khan et al., 2006). The TKE results are shown in Fig. 12. The experimental profile for the radial line $1_{\mathrm{d} 1}$ showed that the production rate increased as a function of the radial coordinate, and two peaks were detected. The first one is $\mathrm{k} / \mathrm{V}^{2}$ tip $\approx 0.016$ 

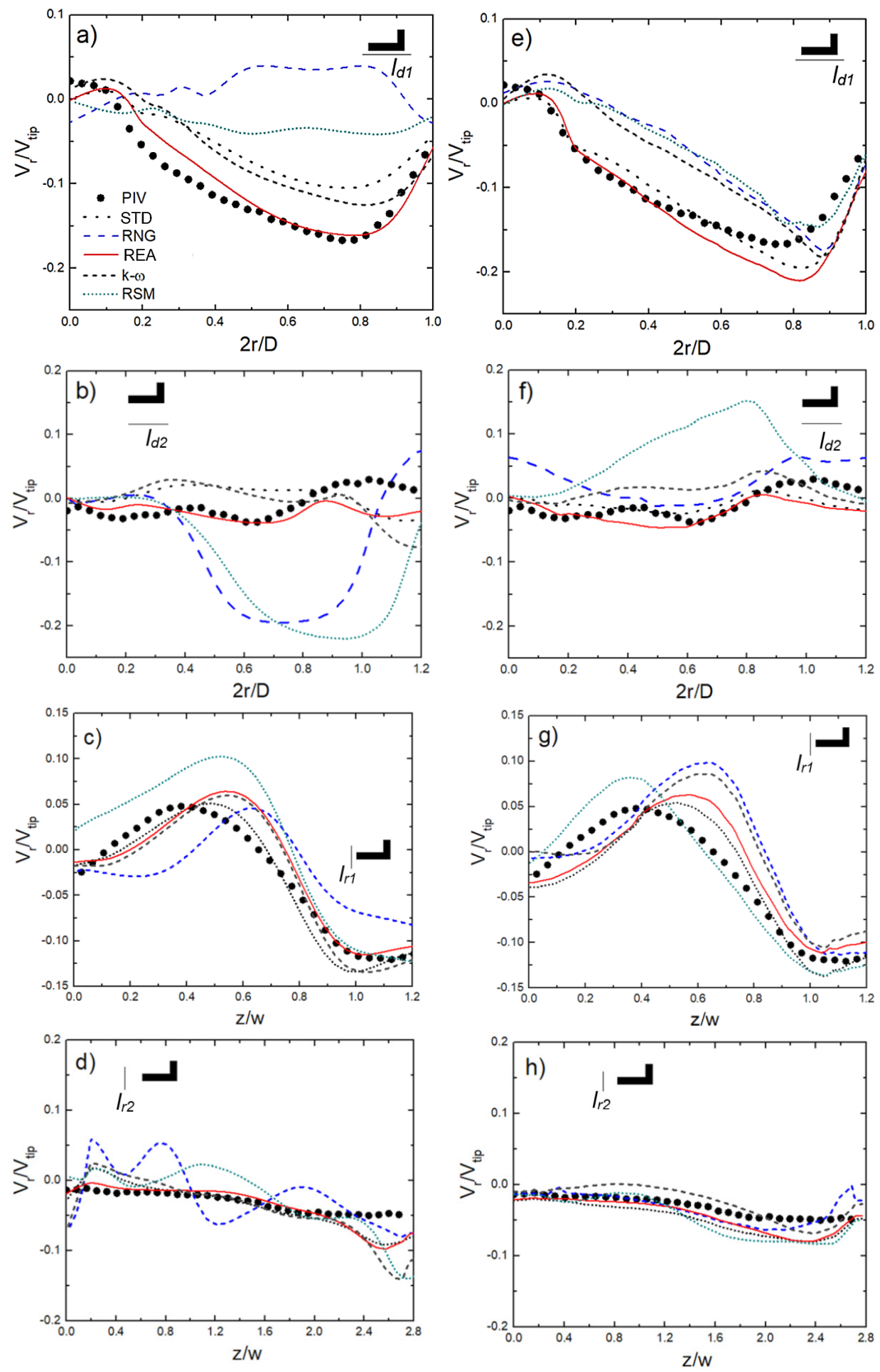

Figure 11. Assessment of the non-dimensional radial velocity profile extracted from the axial and radial pumping lines (see Fig. 7) using the STD, RNG, REA, k- $\omega$ and RSM models. a) - d) CC grid and e) - h) Tetrahedral grid.

near the PBT hub at $2 \mathrm{r} / \mathrm{D} \approx 0.2$ and the another was $\mathrm{k} /$ $\mathrm{V}_{\text {tip }}^{2} \approx 0.02$ near the blade tip at $2 \mathrm{r} / \mathrm{D} \approx 0.9$. Between those peaks, the TKE values showed an almost linear increase. As shown in Figs. 12a and $12 \mathrm{e}$, the RNG, $\mathrm{k}-\omega$ and RSM model profiles were underpredicted for both meshing techniques. By using the CC grid, the STD model overestimated the TKE and the REA profile was underpredicted. Using the tetrahedral grid, the performance of the REA model presented better agreement with the experimental data. The STD model remained overestimated for almost all positions. For the line $1_{\mathrm{d} 2}$, no model could reproduce the high gradient region near the impeller tip shown by the experimental data, where $\mathrm{k} / \mathrm{V}^{2}{ }_{\text {tip }} \approx 0.05$. However, the STD and REA models presented acceptable agreement for the tetrahedral grid for the positions below 2 r/D $<0.6$ and 
$2 \mathrm{r} / \mathrm{D}>1.0$. For the axial line $1_{\mathrm{r} 1}$, low levels of TKE are present, indicating that most of the production takes place inside the discharge region. Independently of the discretization method, the RNG and REA model were able to reproduce adequately the PIV profile. The STD, $k-\omega$ and RSM models failed to reproduce the experimental behavior for the $\mathrm{CC}$ grid (Fig. 12c) as values were substantially overpredicted. For the tetrahedral mesh (Fig. 12g), the STD model presented overestimated values and the rest of the models
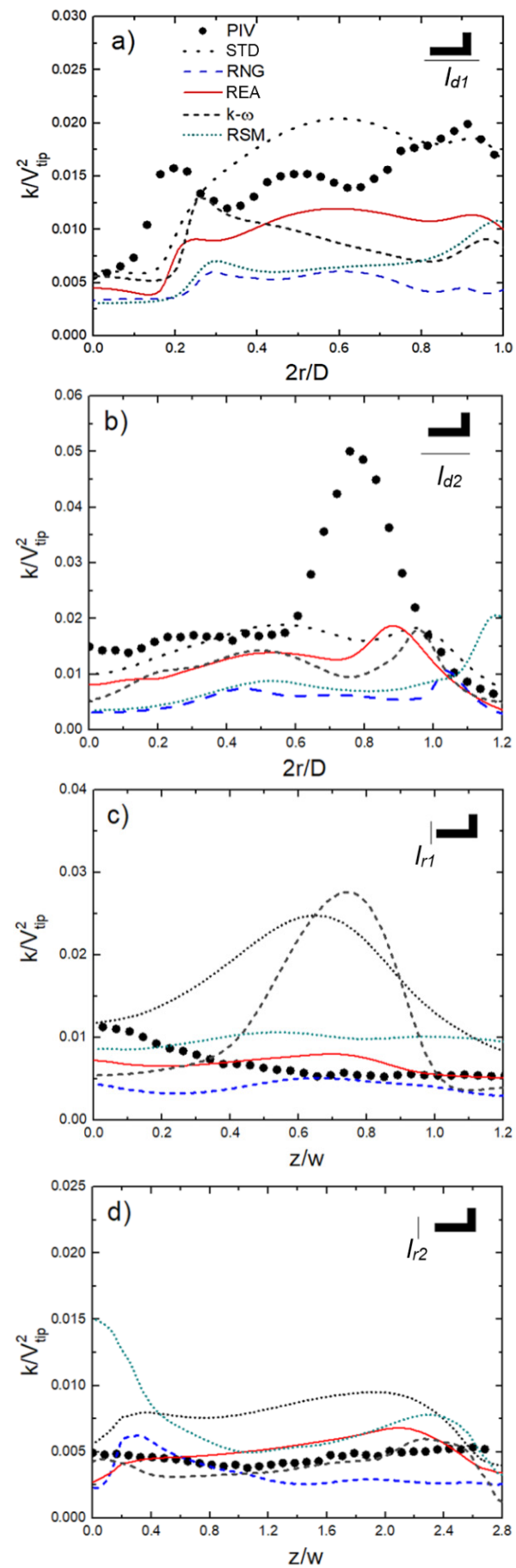

delivered slightly underpredicted values, but showed acceptable agreement with the PIV data. In the axial line $1_{r 2}$, all models presented reasonable predictions for TKE for the CC grid except the STD model. For the tetrahedral mesh, despite slight underpredictions, all turbulence models followed reasonably the experimental profile.

Another important parameter in agitated tank design is the turbulence dissipation rate, which is related to heat transfer, chemical reaction and mixing
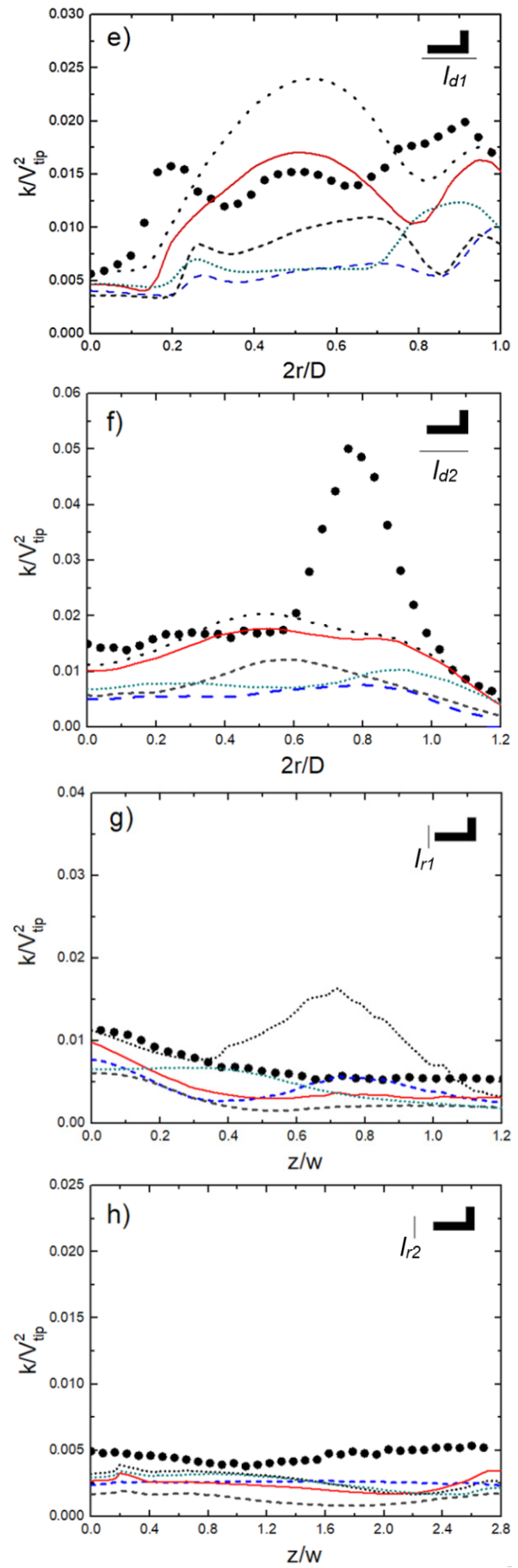

Figure 12. Assessment of the TKE profile for the axial and radial pumping lines obtained with the STD, RNG, REA, k- $\omega$ and RSM models using a) - d) CC grid and e) - h) Tetrahedral grid. 
on the smallest and dissipative scales of the energy cascade. Similarly to the TKE, the non-dimensional turbulence dissipation rate profiles obtained by PIV and shown in Fig. 13 presented larger values in the lines $1_{\mathrm{d} 1}$ and $1_{\mathrm{d} 2}$ in comparison to those of the radial lines, indicating that, in the main stream region, most of the turbulence effects are present. In the radial line close to the impeller discharge $1_{\mathrm{d} 1}$, the STD model presented overestimations in the regions $0.4<2 \mathrm{r} / \mathrm{D}<0.7$ and it
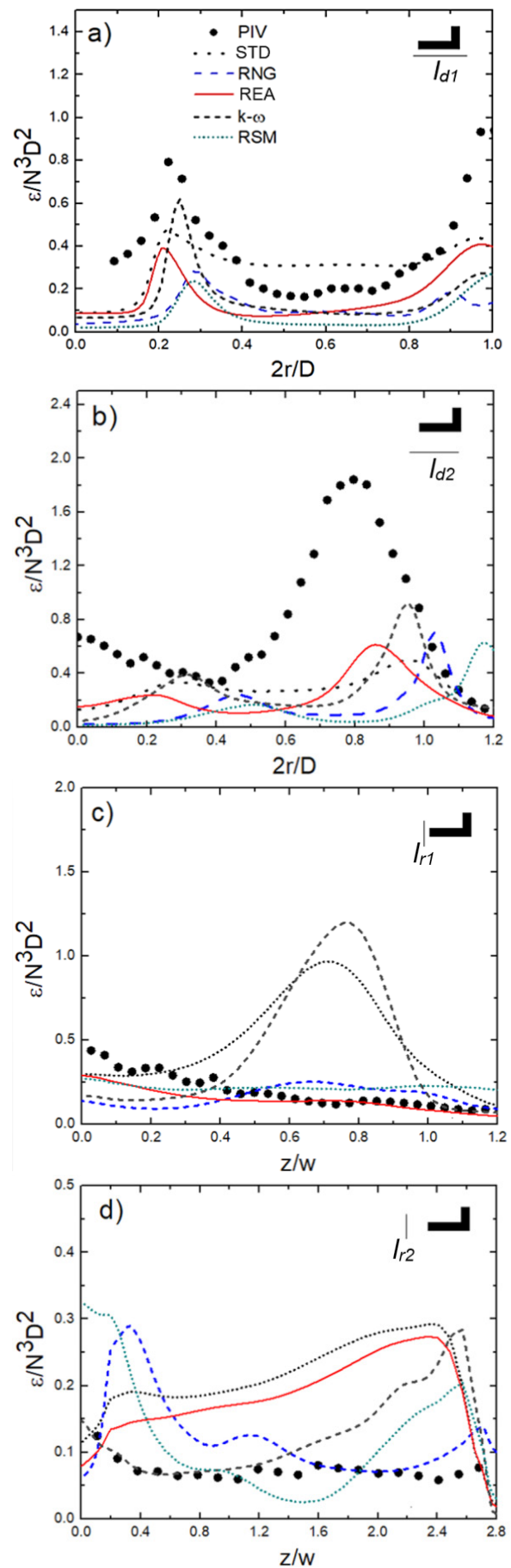

was not able to reproduce the PIV profile, independently of the meshing method. In the CC grid, shown in Fig. $13 \mathrm{a}$, all the models presented underpredicted values. However, the REA and $\mathrm{k}-\omega$ model followed better the bell-shaped behavior exhibited near the hub $(0.1<$ $2 \mathrm{r} / \mathrm{D}<0.4)$ and the steep gradients in the blade tip $(0.8$ $<2 \mathrm{r} / \mathrm{D}<1.0)$ where most of the energy is dissipated. For the tetrahedral grid shown in Fig. 13e, the REA model presented the best agreement regarding the
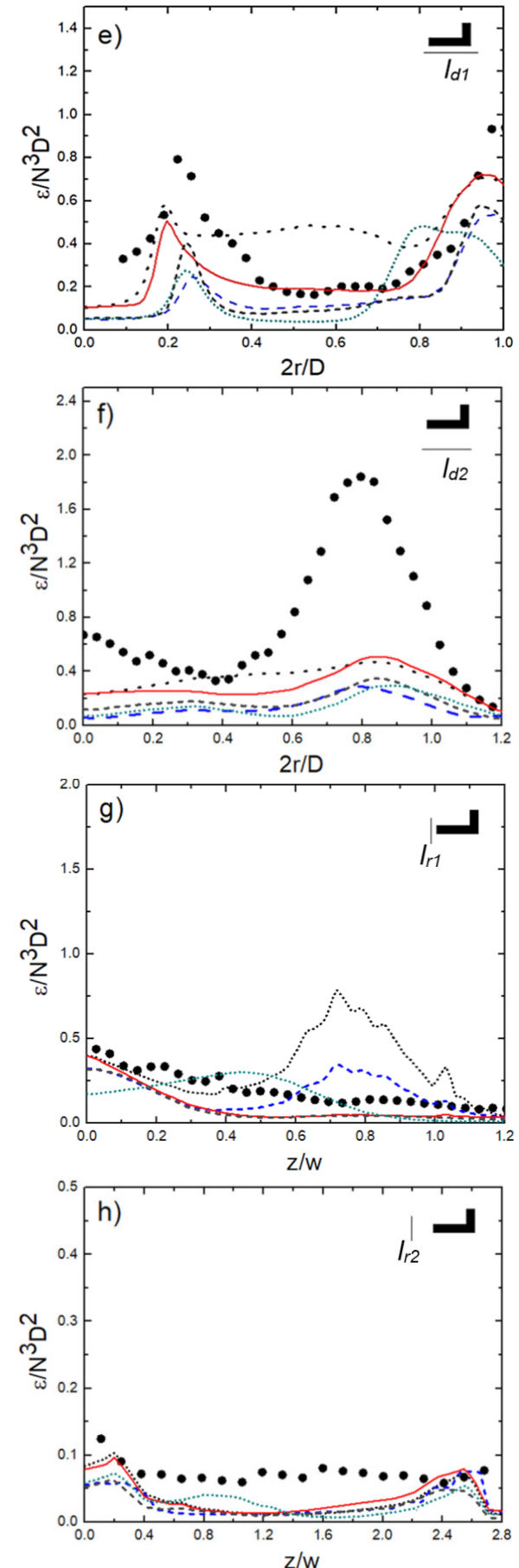

Figure 13. Assessment of the non-dimensional dissipation rate profiles for the axial and radial pumping lines obtained with the STD, RNG, REA, k- $\omega$ and RSM models using a) - d) CC and e) - h) Tetrahedral approaches with respect to the PIV measurements. 
experimental data. Although the profiles of the RNG and RSM models were underpredicted, they presented a better recovery in magnitudes in the high gradient region near the blade tip $(0.8<2 \mathrm{r} / \mathrm{D}<1.0)$. In the line $1_{\mathrm{d} 2}$, all models failed at reproducing the PIV profile. For the CC grid, all CFD profiles showed two peaks of maximum dissipation, which were shifted among them, and with different elongations. The maximum values of these peaks were significantly below the experimental maximum value of $\varepsilon / \mathrm{N}^{3} \mathrm{D}^{2} \approx 2.0$ at $2 \mathrm{r} / \mathrm{D}=$ 0.8 . For the tetrahedral grid, all profiles were severely underpredicted and presented just one peak, at $\approx 2 \mathrm{r} / \mathrm{D}=$ 0.85 . In the radial line $1_{\mathrm{rl}}$ near the PBT blade, for the CC grid, the STD and k- $\omega$ models delivered overestimated values, indicating the false presence of a high gradient region near the blade tip, along its width. The RNG, REA and RSM models presented good agreement with the PIV profile. When a tetrahedral grid was solved, the RNG and STD model presented overestimated values in the zone $(0.5<2 \mathrm{r} / \mathrm{D}<1.2)$. The REA, $\mathrm{k}-\omega$ and RSM profiles presented an acceptable agreement with the PIV profiles, the differences between the REA and $\mathrm{k}-\omega$ profiles being almost negligible. In the line $1_{\mathrm{r} 2}$ and with the CC grid, no model could reproduce the PIV profile, as marked overpredictions were present in most of the positions. The RNG model presented a high gradient zone in an opposite way to the STD, and the RSM model presented two high gradient regions at the beginning and end of the axial line, which are inexistent. For the tetrahedral grids, all models presented similar profiles, which were underpredicted.

As a summary, in order to clarify the discussion presented above, Table 4 present the assessment of all models' performance. In order to quantify the overall capabilities of the models for both velocities and turbulent parameters, the last column presents the percentage of profiles which followed the experimental data.

According to the results, the implementation of a Cartesian meshing did not improve the quality of the simulations, as just the REA model could reproduce more than $60 \%$ of the assessed variables. Another interesting point is the fact that models failed in the dissipation rate prediction. This is expected for the isotropic turbulence assumptions in their formulations. The REA and $k-\omega$ presented the best behavior of all the assessed RANS models, especially under a tetrahedral mesh scheme. The failure of the STD model in the CFD predictions is related to its formulation, which was made considering fully isotropic assumptions. The RNG model, which is based on the Renormalization Group Theory, is supposed to account for rapid strained flows and swirl effects in the transport equations. Under both unstructured meshing schemes, this model presented limitations, especially for the radial velocity predictions near the impeller blade positions and turbulent parameters. Such accuracy problems could be explained considering that the model constants must be adjusted depending on the type of flow (i.e. pipe flow, jet, swirl flow, etc.). This represents a limitation that affected the mean velocity and turbulent predictions in high anisotropic turbulence zones such as those especially found near PBT (Khan et al., 2006; Sharp and Adrian, 2001). The formulation of the REA model involves an improved eddy viscosity and a dissipation transport equation related to the vorticity fluctuations, which made this model suitable for the local strain rates and swirling flow predictions (Shih et al., 1995). For the most of the parameters, the REA model presented the better performance in both type of grids. Another model which presented fair agreement with the experimental data, especially using a tetrahedral grid, is the $\mathrm{k}-\omega$ model (Wilcox, 1993). In this case, the specific dissipation rate is modeled in the second transport equation instead of the dissipation rate, giving good predictions in mixing layers and shear rates such as those existing in agitated tanks. Finally, the RSM model implementation, which is not based on the isotropy assumption, did not show any superior feature. As its resolution involves the

Table 4. Comparison of the prediction capabilities of the mean velocity and turbulent profiles.

\begin{tabular}{|c|c|c|c|c|c|c|c|c|c|c|c|c|c|c|c|c|c|}
\hline \multicolumn{18}{|c|}{ Cartesian Meshing } \\
\hline & \multicolumn{4}{|c|}{$\mathbf{V}_{\mathrm{a}}$} & \multicolumn{4}{|c|}{$\mathbf{V}_{\mathbf{r}}$} & \multicolumn{4}{|c|}{$\kappa$} & \multicolumn{4}{|c|}{$\varepsilon / \mathbf{N}^{3} \mathbf{D}^{2}$} & \multirow{2}{*}{$(\%)$} \\
\hline & $I_{d 1}$ & $\mathbf{l}_{\mathrm{d} 2}$ & $l_{r 1}$ & $I_{\mathrm{r} 2}$ & $I_{d 1}$ & $\mathbf{l}_{\mathrm{d} 2}$ & $I_{r 1}$ & $I_{\mathrm{r} 2}$ & $l_{d 1}$ & $I_{d 2}$ & $l_{\mathbf{r} 1}$ & $l_{\mathrm{r} 2}$ & $\mathbf{I}_{\mathrm{d} 1}$ & $I_{d 2}$ & $l_{\mathrm{r} 1}$ & $I_{\mathrm{r} 2}$ & \\
\hline STD & $\checkmark$ & $\checkmark$ & $\checkmark$ & $\mathrm{x}$ & $\mathrm{x}$ & $\checkmark$ & $\sqrt{ }$ & $\checkmark$ & $\mathrm{x}$ & $\mathrm{x}$ & $\mathrm{x}$ & $\mathrm{x}$ & $\mathrm{x}$ & $\mathrm{x}$ & $\mathrm{x}$ & $\mathrm{x}$ & 38 \\
\hline RNG & $\checkmark$ & $\mathrm{x}$ & $\mathrm{x}$ & $\mathrm{x}$ & $\mathrm{X}$ & $\mathrm{x}$ & $\mathrm{x}$ & $\checkmark$ & $\mathrm{x}$ & $\mathrm{x}$ & $\checkmark$ & $\checkmark$ & $\mathrm{x}$ & $\mathrm{x}$ & $\checkmark$ & $\mathrm{x}$ & 31 \\
\hline REA & $\checkmark$ & $\checkmark$ & $\checkmark$ & $\mathrm{x}$ & $\checkmark$ & $\checkmark$ & $\checkmark$ & $\checkmark$ & $\mathrm{x}$ & $\mathrm{x}$ & $\checkmark$ & $\checkmark$ & $\mathrm{x}$ & $\mathrm{x}$ & $\checkmark$ & $\mathrm{x}$ & 63 \\
\hline$k-\omega$ & $\checkmark$ & $\checkmark$ & $\checkmark$ & $\mathrm{x}$ & $\mathrm{x}$ & $\checkmark$ & $\checkmark$ & $\checkmark$ & $\mathrm{x}$ & $\mathrm{x}$ & $\mathrm{x}$ & $\checkmark$ & $\mathrm{x}$ & $\mathrm{x}$ & $\mathrm{x}$ & $\mathrm{x}$ & 44 \\
\hline RSM & $\checkmark$ & $\mathrm{x}$ & $\checkmark$ & $\mathrm{x}$ & $\mathrm{x}$ & $\mathrm{x}$ & $\mathrm{X}$ & $\checkmark$ & $\mathrm{x}$ & $\mathrm{x}$ & $\mathrm{x}$ & $\checkmark$ & $\mathrm{x}$ & $\mathrm{x}$ & $\checkmark$ & $\mathrm{x}$ & 31 \\
\hline \multicolumn{18}{|c|}{ Tetrahedral Meshing } \\
\hline & \multicolumn{4}{|c|}{$\mathbf{V}_{\mathrm{a}}$} & \multicolumn{4}{|c|}{$\mathbf{V}_{\mathbf{r}}$} & \multicolumn{4}{|c|}{$\boldsymbol{\kappa}$} & \multicolumn{4}{|c|}{$\varepsilon / \mathbf{N}^{3} \mathbf{D}^{2}$} & $(0)$ \\
\hline & $\mathbf{l}_{\mathrm{d} 1}$ & $\mathbf{l}_{\mathrm{d} 2}$ & $l_{\mathbf{r} 1}$ & $I_{\mathrm{r} 2}$ & $\underline{I}_{\mathrm{d} 1}$ & $\mathbf{l}_{\mathrm{d} 2}$ & $\underline{l}_{\mathbf{r} 1}$ & $I_{\mathrm{r} 2}$ & $\mathbf{l}_{\mathrm{d} 1}$ & $I_{d 2}$ & $l_{\mathbf{r} 1}$ & $l_{\mathrm{r} 2}$ & $\mathbf{l}_{\mathrm{d} 1}$ & $\mathbf{I}_{\mathrm{d} 2}$ & $l_{\mathrm{r} 1}$ & $I_{\mathrm{r} 2}$ & \\
\hline STD & $\checkmark$ & $\checkmark$ & $\checkmark$ & $\mathrm{x}$ & $\mathrm{x}$ & $\checkmark$ & $\checkmark$ & $\checkmark$ & $\mathrm{x}$ & $\mathrm{x}$ & $\mathrm{x}$ & $\checkmark$ & $\mathrm{x}$ & $\mathrm{x}$ & $\mathrm{x}$ & $\mathrm{x}$ & 44 \\
\hline RNG & $\checkmark$ & $\checkmark$ & $\checkmark$ & $\checkmark$ & $\mathrm{x}$ & $\checkmark$ & $\mathrm{x}$ & $\checkmark$ & $\mathrm{x}$ & $x$ & $\checkmark$ & $\checkmark$ & $\mathrm{x}$ & $\mathrm{x}$ & $x$ & $\mathrm{x}$ & 50 \\
\hline REA & $\checkmark$ & $\checkmark$ & $\checkmark$ & $\checkmark$ & $\checkmark$ & $\checkmark$ & $\checkmark$ & $\checkmark$ & $\checkmark$ & $x$ & $\checkmark$ & $\checkmark$ & $\checkmark$ & $\mathrm{x}$ & $\checkmark$ & $\mathrm{x}$ & 81 \\
\hline$k-\omega$ & $\checkmark$ & $\checkmark$ & $\checkmark$ & $\checkmark$ & $\checkmark$ & $\checkmark$ & $\mathrm{x}$ & $\checkmark$ & $\mathrm{x}$ & $x$ & $\checkmark$ & $\checkmark$ & $\mathrm{x}$ & $\mathrm{x}$ & $\checkmark$ & $\mathrm{x}$ & 63 \\
\hline RSM & $\checkmark$ & $\checkmark$ & $\mathrm{x}$ & $\mathrm{x}$ & $\mathrm{x}$ & $\mathrm{x}$ & $\mathrm{x}$ & $\checkmark$ & $\mathrm{x}$ & $\mathrm{x}$ & $\checkmark$ & $\checkmark$ & $\mathrm{x}$ & $\mathrm{x}$ & $\checkmark$ & $\mathrm{x}$ & 38 \\
\hline
\end{tabular}


inclusion of one transport equation for each Reynold Stress component, seven additional equations must be resolved, increasing the time consumption. The deviations found in the RSM model could be connected to the closure assumptions of its formulation, which are performed in terms that are difficult to measure such as the pressure-strain or others related to the dissipation rate (Ansys, 2009).

\section{Maps of the velocities, $\kappa$ and $\varepsilon$}

As changes in profiles are related to flow distributions, Figs. 14 and 15 show the flow parameters of the two RANS models that presented the better performance, (REA and k- $\omega$ ), under the CC or tetrahedral grids in comparison to the PIV maps. The response of the CC grids (Fig. 14) for the nondimensional axial velocity showed that both turbulence models were able to capture the high gradient region present below the impeller. As expected, it is related to the good prediction capabilities for $\mathrm{N}_{\mathrm{q}}$. It is important to note that, near the interphase between the rotational and non-rotational zones, a region with a stagnated flow appears. This region was not present in the measurements, and it is attributed to numerical issues which could be prejudicial in the CFD performance when CC grids are used. The non-dimensional radial velocity shown in the second column of Fig. 14, showed a good agreement of the REA model with the PIV map in the PBT vicinity, where $\mathrm{V}_{\mathrm{r}} / \mathrm{V}_{\text {tip }} \approx-0.15$. In the low down pumping region where radial velocity has positive values of $\mathrm{V}_{\mathrm{r}} / \mathrm{V}_{\text {tip }} \approx 0.15$, the gradients were different from those measured, and values were generally overestimated.

The experimental TKE showed a distinctive circular region of high intensity near the impeller blade of $\mathrm{k} / \mathrm{V}^{2}$ tip $\approx 0.04$ which is elongated in the pumping direction and spreads out covering almost all the discharge region. Although the overall extension of the region influenced by the TKE was fairly well predicted by the REA model, both models failed to reproduce the high TKE region below the impeller blade, and values were underpredicted. The $\varepsilon^{*}$ maps obtained from PIV resembled the TKE maps. Although with slightly distorted shape and with subestimated values $\left(\varepsilon^{*} \approx 15\right.$, the RANS models were able to reproduce the high $\varepsilon^{*}$ region in the PBT discharge. The overall shape of the zone influenced by $\varepsilon^{*}$ was better predicted by the REA model. Regarding Fig. 15 (tetrahedral grid), the axial velocity maps were well predicted for both RANS models. In this case, the issues of the interphase boundary condition were smaller in comparison to those of the Cartesian grid. For the radial velocity component, the high gradient region of $\mathrm{V}_{\mathrm{r}} / \mathrm{V}_{\text {tip }} \approx-0.15$ was adequately captured by both models. Far in the
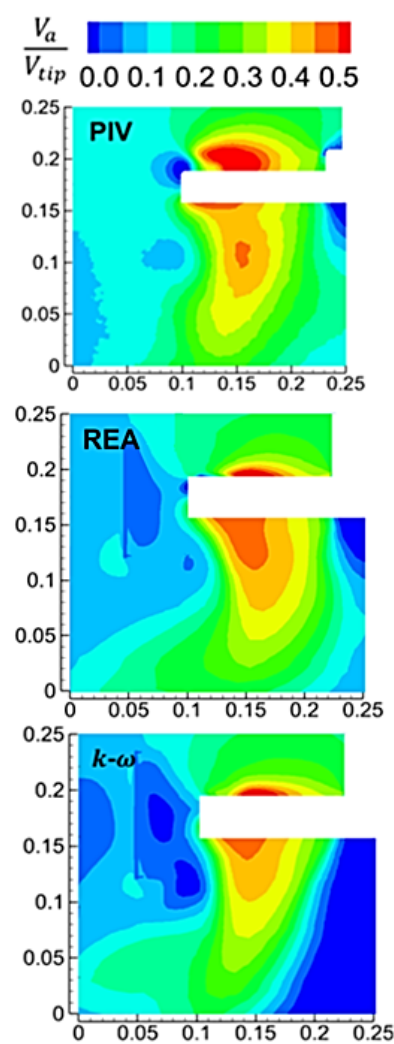
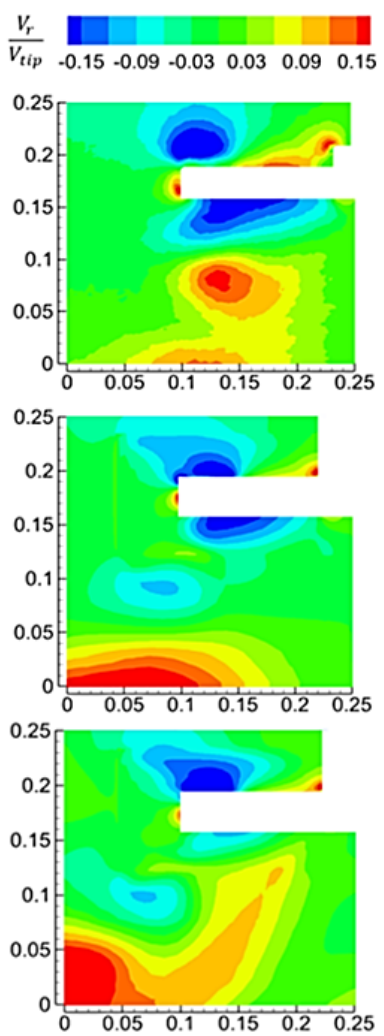
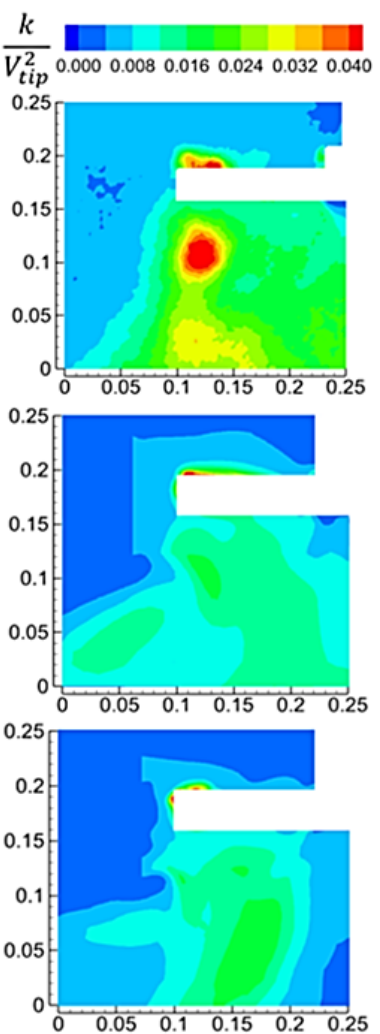
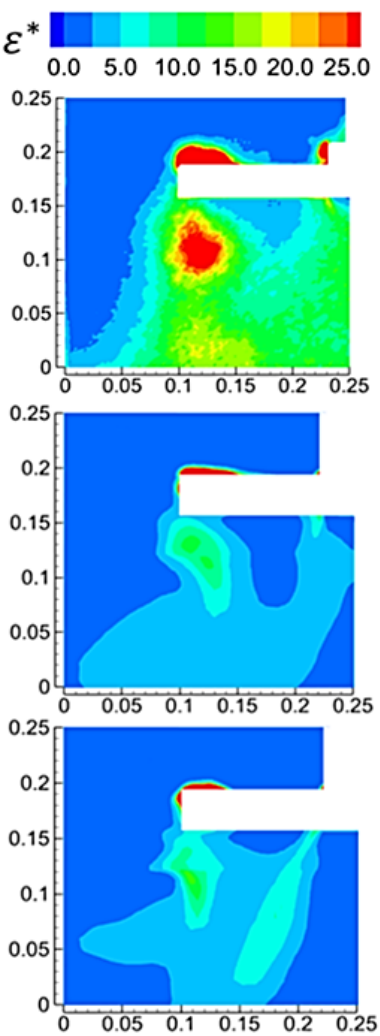

Figure 14. Assessment of the non-dimensional axial velocity, radial velocity, TKE and $\varepsilon$ contour maps obtained with the REA and k- $\omega$ models using the CC grid with respect to the PIV measurements (first row in the Figure). Here the axes refer to $\mathrm{x} / \mathrm{T}$ and $\mathrm{y} / \mathrm{T}$. 

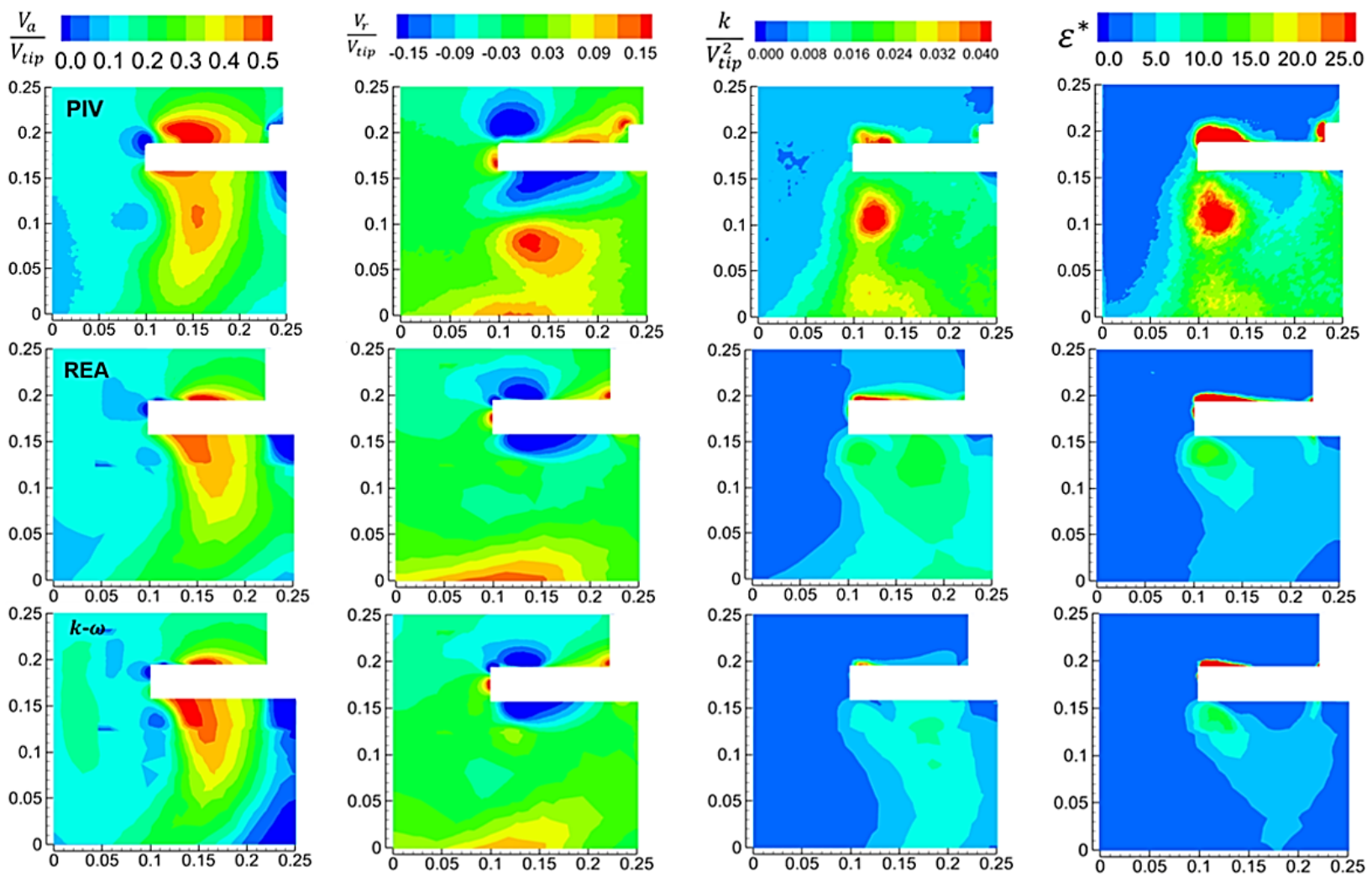

Figure 15. Assessment of the non-dimensional axial velocity, radial velocity, TKE and $\varepsilon$ contour maps obtained with the REA and $\mathrm{k}-\omega$ models using the tetrahedral grid with respect to the PIV measurements. The $\mathrm{x}-\mathrm{y}$ axes refer to $\mathrm{x} / \mathrm{T}$ and $\mathrm{y} / \mathrm{T}$.
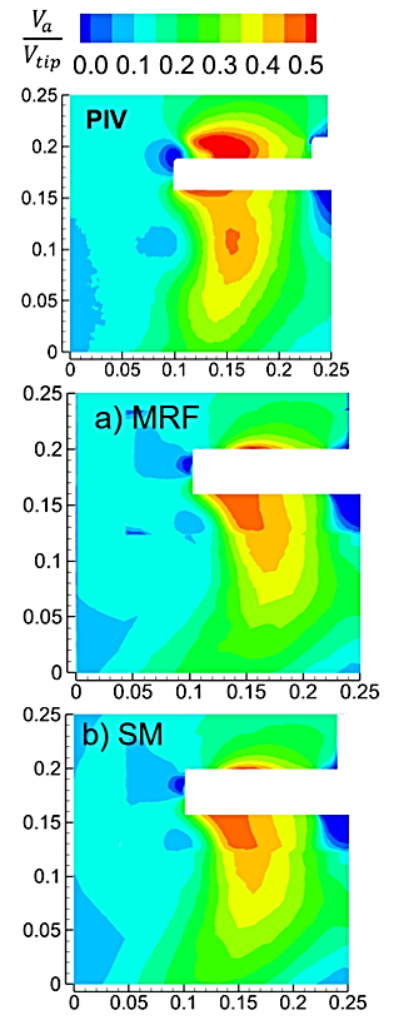
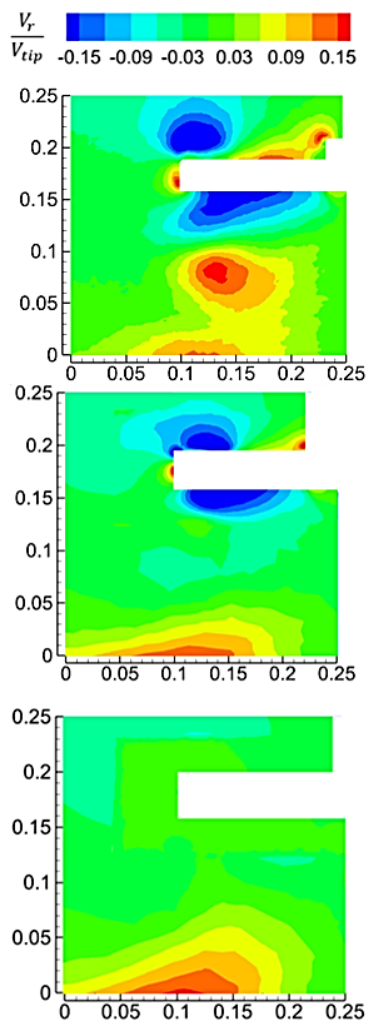
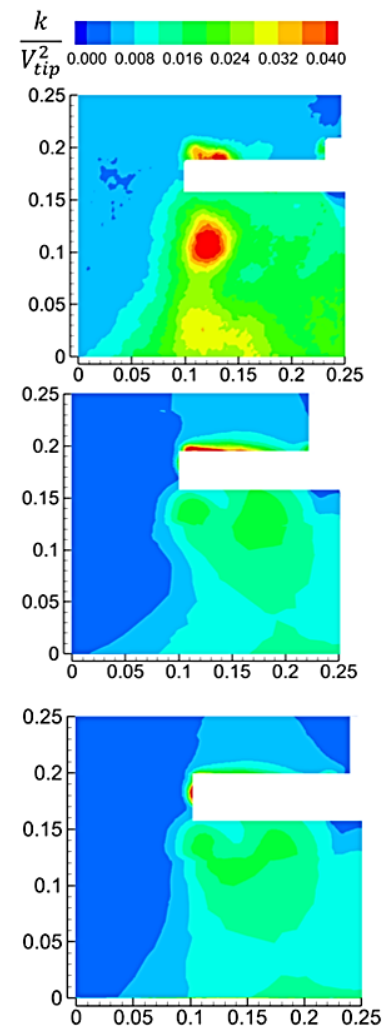
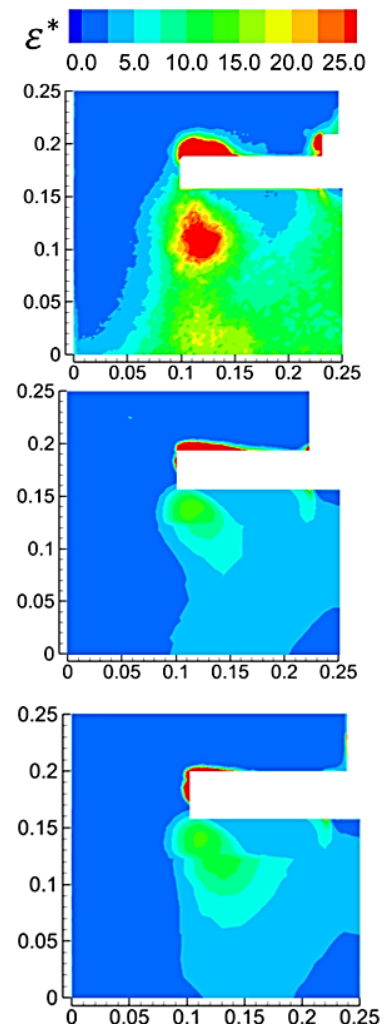

Figure 16. Assessment of the non-dimensional axial velocity, radial velocity, TKE and $\varepsilon$ contour maps obtained for the steady and unsteady modeling approaches: First row refers to PIV measurements, a) MRF approach, b) Sliding mesh simulations. The $\mathrm{x}-\mathrm{y}$ axes refer to $\mathrm{x} / \mathrm{T}$ and $\mathrm{y} / \mathrm{T}$. 
discharge region, neither turbulence model was able to reproduce the high gradient region of maximum $\mathrm{V}$ / $\mathrm{V}_{\text {tip }} \approx 0.15$. The overall extent and shape of the TKE region was well predicted by the REA model, and neither model was able to map the high gradient region of $\mathrm{k} / \mathrm{V}^{2} \approx 0.04$. Though with subpredicted values, the region of high dissipation rate in the discharge, near the PBT tip predicted by the REA and $\mathrm{k}-\omega$ models under the tetrahedral grid followed better the semicircular shape present in the PIV map in comparison with the Cartesian approach. Again, the extension of the zone influenced by $\varepsilon^{*}$ was better reproduced by the REA model.

\section{The influence of the temporal term (SM simulations)}

In order to assess the influence of the inclusion of the temporal term in the case which delivered the best predictions, a Sliding Mesh simulation for the REA model under the tetrahedral grid was performed. From Fig. 16, which presents a comparison of the SM with the MRF and PIV results, the radial velocity map for the SM deviated from that measured by PIV. For the other variables, negligible changes were obtained. The predicted $\mathrm{N}_{\mathrm{p}-\varepsilon}$ for the SM was 0.91 , this value being subpredicted and similar to the 0.97 value obtained from the MRF model. The latter is a clear evidence that the inclusion of the temporal term in the simulations is not justified when a description based on mean values is desired. Also the simulation time increases significantly, and the post-processing task become more tedious.

\section{CONCLUSIONS}

The assessment of the RANS-based models Standard $\kappa-\varepsilon$, RNG, Realizable, $\mathrm{k}-\omega$ and RSM with unstructured grids has been completed for the turbulent flow of a tank stirred by a PBT at fully turbulent flow. The performance of the grids composed of Cut-Cell and Tetrahedral elements was compared to establish guidance in the discretization of complex domains. From the grid independence analysis, the $\mathrm{N}_{\mathrm{p}}$ derived from the numerical shaft torque and $\mathrm{N}_{\mathrm{q}}$ were found to be independent of the cell number and meshing method. A strong dependence of the power number, obtained from the dissipated power, was found with respect to the cell number for both meshing approaches. For tetrahedral grids, the values of $\mathrm{N}_{\mathrm{p}-\varepsilon}$ were underestimated in comparison to the experimental value, even for the fine grid of 6.1 million cells. On the other hand, with the Cut-Cell grid, the $\mathrm{N}_{\mathrm{p}-\varepsilon}$ predictions improved, as values deviated less than $10 \%$ for the 3.6 and 6.2 million cell grids. The $\mathrm{N}_{\mathrm{p}}, \mathrm{N}_{\mathrm{p}-\varepsilon}$ and $\mathrm{N}_{\mathrm{q}}$ were fairly well predicted for the Realizable and k- $\omega$ models, especially for the Cut-Cell grid, while the same models presented underestimated values for $\mathrm{N}_{\mathrm{p}-\varepsilon}$ when the tetrahedral meshing was used. The influence of the inclusion of the swirl number in the RNG model and the k- $\omega$ SST model did not cause visible improvement in either the $\mathrm{N}_{\mathrm{p}}, \mathrm{N}_{\mathrm{p}-\varepsilon}, \mathrm{N}_{\mathrm{q}}$ or in the profiles of production and dissipation rates when compared to their original models. Finally, by its formulation, which accounts for high strain rates and shear flows, such as those found in the pumping region, the Realizable and $k-\omega$ models performed better for the tetrahedral grid than with the Cut-Cell grid in most of the measured variables. A slight superiority is present for the realizable model predictions for the dissipation rate in comparison with the $\mathrm{k}-\omega$, and it should be implemented in MRF simulations for more complex flows such as multiphase, with heat transfer and/or chemical reaction. It is important to point out that the RSM model, which accounts for anisotropy, had the worst performance of all the models, which could be related to the increased amount of solved equations (numerical diffusivity issues), as well as model assumptions made in terms which are difficult to measure such as the Pressure-Strain. Finally, from the Sliding Mesh simulations, no important improvements for the mean quantities are obtained by the inclusion of the temporal term, marginal improvements were present for the dissipation rate, and the time of the simulation was strongly increased. Some limitations of this work that require further analysis are the influence of the enhanced wall treatment option at the blade walls, the use of polyhedral cells, or the inclusion of chemical reaction models, multiphase flow or thermally affected boundary layers.

\section{ACKNOWLEDGEMENTS}

The authors wish to express their acknowledgement to the Consejo Nacional de Ciencia y Tecnología (CONACyT), for the support provided for this research, through the Basic Science project CB2011/169786. Thanks are also due to the Centro de Ingeniería y Desarrollo Industrial (CIDESI) for the facilities provided during the accomplishment of this work. Authors would like to thank the anonymous reviewers for their careful reading and insightful comments.

\section{NOMENCLATURE}

$\begin{array}{ll}\mathrm{C}_{\mathrm{s}} & \text { Smagorinsky constant } \\ \mathrm{D} & \text { Diameter }[\mathrm{m}] \\ \mathrm{H} & \text { Tank height }[\mathrm{m}] \\ 1_{\mathrm{d} 1} & \text { Discharge line 1 } \\ 1_{\mathrm{d} 2} & \text { Discharge line 2 } \\ 1_{\mathrm{r} 1} & \text { Radial line 1 } \\ 1_{\mathrm{r} 2} & \text { Radial line 2 } \\ \mathrm{N} & \text { Angular velocity }\left[\mathrm{s}^{-1}\right]\end{array}$




$\begin{array}{ll}\mathrm{N}_{\mathrm{p}} & \text { Power number } \\ \mathrm{N}_{\mathrm{p}-\varepsilon} & \text { Power number from dissipation rate } \\ \mathrm{N}_{\mathrm{q}} & \text { Pumping number } \\ \mathrm{P}^{\mathrm{a}} & \text { Power [W] } \\ \mathrm{Q} & \text { Mass flow rate }\left[\mathrm{kg} \cdot \mathrm{s}^{-1}\right] \\ \mathrm{r} & \text { Radius }[\mathrm{m}] \\ \mathrm{Re} & \text { Reynolds number } \\ \mathrm{T} & \text { Tank diameter }[\mathrm{m}] \\ \mathrm{V}_{\text {tip }} & \text { Velocity at blade tip }\left[\mathrm{m} \cdot \mathrm{s}^{-1}\right] \\ \mathrm{M} & \text { Torque }[\mathrm{N} \cdot \mathrm{m}]\end{array}$

\section{Greek symbols}

$\alpha \quad$ Swirl constant

$\Delta \quad$ PIV spatial resolution [m]

$\Delta \mathrm{t} \quad$ Time step [s]

$\varepsilon \quad$ Turbulent dissipation rate $\left[\mathrm{W} \cdot \mathrm{kg}^{-1}\right]$

$\varepsilon^{*} \quad$ Non-dimensional turbulence dissipation rate

$\varepsilon_{\mathrm{T}} \quad$ Turbulence dissipation rate from torque measurements $\left[\mathrm{W} \cdot \mathrm{kg}^{-1}\right]$

$k \quad$ Turbulence kinetic energy $\left[\mathrm{J}^{\mathrm{kg}} \mathrm{kg}^{-1}\right]$

$\lambda_{\mathrm{K}} \quad$ Kolmogorov length scale $[\mathrm{m}]$

$\mu \quad$ Dynamic viscosity [Pa $\cdot \mathrm{s}]$

$\rho \quad$ Density $\left[\mathrm{kg} \cdot \mathrm{m}^{-3}\right]$

\section{Acronyms}

CFD Computational fluid dynamics

DNS Direct Numerical Simulation

LES Large eddy simulation

MRF Multiple reference frame

LDV Laser Doppler velocimetry

PBT Pitched blade turbine

PIV Particle image velocimetry

RANS Reynolds average Navier Stokes

SGS Subgrid scale model

SM Sliding mesh

STR Stirred tank reactors

TKE Turbulence kinetic energy

\section{REFERENCES}

Achouri, R., Mokni, I., Mhiri, H. and Bournot, P., A 3D CFD Simulation of a Self Inducing Pitched Blade Turbine Downflow, Energy Conversion Management, 64, 633-641 (2012). https://doi. org/10.1016/j.enconman.2012.06.005

Alcamo, R., Micale, G., Grisafi, F., Brucato, A. and Ciofalo, M., Large-Eddy Simulation of Turbulent Flow in an Unbaffled Stirred Tank Driven by a Rushton Turbine, Chemical Engineering Science, 60, 2303-2316 (2005). https://doi.org/10.1016/j. ces.2004.11.017

Andersson, B., Andersson, R., Hakansson, L., Mortensen, M., Sudiyo, R. and Van Wachem, B., Computational Fluid Dynamics for Engineers. Cambridge University Press. New York (2012). https://doi.org/10.1017/CBO9781139093590
Ansys, User's Guide, Ansys-Fluent, Central Resource Park, 10 Cavendish Court, Lebanon, USA (2009).

Aubin, J., Fletcher, D.F. and Xuereb, C., Modeling Turbulent Flow in Stirred Tanks with CFD: The influence of the Modeling Approach, Turbulence Model and Numerical Scheme, Experimental Thermal and Fluid Sciences, 28, 431-445 (2004). https://doi.org/10.1016/j. expthermflusci.2003.04.001

Aubin, J., Mavros, P., Fletcher, D.F., Bertrand, J. and Xuereb, C., Effect of Axial Agitator Configuration (Up-Pumping, Down-Pumping, Reverse Rotation) on Flow Patterns Generated in Stirred Vessels, Chemical Engineering Research and Design, 79, 845-856 (2001). https://doi. org/10.1205/02638760152721046

Bhattacharya, S. and Kresta, S.M., CFD Simulations of Three-Dimensional Wall Jets in a Stirred Tank, Canadian Journal of Chemical Engineering, 80, 1-15 (2008). https://doi.org/10.1002/cjce.5450800405

Chapple, D., Kresta, S.M., Wall, A. and Afacan, A., The effect of Impeller and Tank Geometry on Power Number for a Pitched Blade Turbine, Chemical Engineering Research and Design 80, 364-372 (2002). https://doi. org/10.1205/026387602317446407

Coroneo, M., Montante, G., Paglianti, A. and Magelli, F., CFD Prediction of Fluid Flow and Mixing in Stirred Tanks: Numerical Issues About the RANS Simulations, Computers \& Chemical Engineering, 35, 1959-1968 (2011). https://doi.org/10.1016/j. compchemeng.2010.12.007

Delafosse, A., Line, A., Morchain, J., and Guiraud, P., LES and URANS Simulations of Hydrodynamics in Mixing Tank: Comparison to PIV Experiments, Chemical Engineering Research and Design, 86, 1322-1330 (2008). https://doi.org/10.1016/j. cherd.2008.07.008

Devals, C., Heniche, M., Takenaka, K. and Tanguy, P.A., CFD Analysis of Several Design Parameters Affecting the Performance of the Maxblend Impeller, Computers \& Chemical Engineering, 32, 1831-1841 (2008). https://doi.org/10.1016/j. compchemeng.2007.09.007

Ge, C.Y., Wang, J.J., Gu, X.P. and Feng, L.F., CFD Simulation and PIV Measurement of the Flow Field Generated by Modified Pitched Blade Turbine Impellers, Chemical Engineering Research and Design, 92, 1027-1036 (2014). https://doi. org/10.1016/j.cherd.2013.08.024

Jaworski, Z., Wyszynski, M.L., Moore, I.P.T. and Nienow, A.W., Sliding Mesh Computational Fluid Dynamics - A Predictive Tool in Stirred Tank Design, Proceedings of the Institution of Mechanical Engineers, Part E: Journal of Process Mechanical Engineering, 211, 149-156 (1997). https://doi.org/10.1243/0954408971529638 
Jaworski, Z. and Zakrzewska, B., Modelling of the Turbulent Wall Jet Generated by a Pitched Blade Turbine Impeller, Chemical Engineering Research and Design, 80, 846-854 (2002). https://doi. org/10.1205/026387602321143381

Jiang, X. and Lai, H., Numerical Techniques for Direct and Large-Eddy Simulations. CRC Press, Florida (2009).

Joshi, J.B., Nere, N.K., Rane, C. V., Murthy, B.N., Mathpati, C.S., Patwardhan, A.W. and Ranade, V. V., CFD simulation of Stirred Tanks: Comparison of Turbulence Models. Part I: Radial Flow Impellers, Canadian Journal of Chemical Engineering, 89, 23-82 (2011a). https://doi.org/10.1002/cjce.20446

Joshi, J.B., Nere, N.K., Rane, C. V., Murthy, B.N., Mathpati, C.S., Patwardhan, A.W. and Ranade, V. V., CFD Simulation of Stirred Tanks: Comparison of Turbulence Models (Part II: Axial Flow Impellers, Multiple Impellers and Multiphase Dispersions), Canadian Journal of Chemical Engineering, 89, 754816 (2011b). https://doi.org/10.1002/cjce.20465

Karimi, M., Akdogan, G. and Bradshaw, S.M., Effects of Different Mesh Schemes and Turbulence Models in CFD Modelling of Stirred Tanks, Physicochemical Problems of Mineral Processing, 48, 513-531 (2012).

Kasat, G.R., Khopkar, A.R., Ranade, V. V. and Pandit, A.B., CFD Simulation of Liquid-Phase Mixing in Solid-Liquid Stirred Reactor, Chemical Engineering Science, 63, 3877-3885 (2008). https://doi.org/10.1016/j.ces.2008.04.018

Khan, F.R., Investigation of turbulent flows and instabilities in a stirred vessel using particle image velocimetry, $\mathrm{PhD}$ Thesis, Loughborough University (2005).

Khan, F.R., Rielly, C.D. and Brown, D.A.R., AngleResolved Stereo-PIV Measurements Close to a Down-Pumping Pitched-Blade Turbine, Chemical Engineering Science, 61, 2799-2806 (2006). https://doi.org/10.1016/j.ces.2005.10.067

Kirkpatrick, M.P., Armfield, S.W. and Kent, J.H., A Representation of Curved Boundaries for the Solution of the Navier-Stokes Equations on a Staggered Three-Dimensional Cartesian Grid, Journal of Computational Physics, 184, 1-36(2003). https://doi.org/10.1016/S0021-9991(02)00013-X

Kresta, S.M. and Wood, P.E., The Flow Field Produced by a Pitched Blade Turbine: Characterization of the Turbulence and Estimation of the Dissipation Rate, ChemicalEngineering Science, 48, 1761-1774(1993). https://doi.org/10.1016/0009-2509(93)80346-R

Lane, G.L., Improving the Accuracy of CFD Predictions of Turbulence in a Tank Stirred by a Hydrofoil Impeller, Chemical Engineering Science, 169, 188-211 (2017). https://doi.org/10.1016/j. ces.2017.03.061
Mao, D., Feng, L., Wang, K.A.I. and Li, Y., The Mean Flow Field Generated by a Pitched Blade Turbine: Changes in the Circulation Pattern Due to Impeller Geometry, Canadian Journal of Chemical Engineering, 75, 307-316 (1997). https://doi. org/10.1002/cjce.5450750205

Martinez-Delgadillo,S.,Mollinedo-Ponce,H.,MendozaEscamilla, V., Gutiérrez-Torres, C., Jiménez-Bernal, J. and Barrera-Diaz, C., Performance Evaluation of an Electrochemical Reactor used to Reduce $\mathrm{Cr}(\mathrm{VI})$ from Aqueous Media Applying CFD Simulations, J. Clean. Prod. 34, 120-124 (2012). https://doi. org/10.1016/j.jclepro.2011.10.036

Meyers, J. and Sagaut, P., On the Model Coefficients for the Standard and the Variational Multi-Scale Smagorinsky Model, Journal of Fluid Mechanics, 569, 287-319 (2006). https://doi.org/10.1017/ S0022112006002850

Murthy, B.N. and Joshi, J.B., Assessment of Standard $\mathrm{k}-\varepsilon, \mathrm{RSM}$ and LES Turbulence Models in a Baffled Stirred Vessel Agitated by Various Impeller Designs, Chemical Engineering Science, 63, 5468-5495 (2008). https://doi.org/10.1016/j.ces.2008.06.019

Ng, K., Fentiman, N.J., Lee, K.C. and Yianneskis, M., Assessment of Sliding Mesh CFD Predictions and LDA Measurements of the Flow in a Tank Stirred by a Rushton Impeller. Chemical engineering research and desigin, 76, 737-747 (1998). https:// doi.org/10.1205/026387698525315

Roache, P.J., Perspective a Method for Uniform Reporting of Grid Refinement Studies, Journal of Fluids Engineering, 116, 405-413 (1994). https:// doi.org/10.1115/1.2910291

Rutherford, K., Mahmoudi, S., Lee, K. and Yianneskis, M., The Influence of Rushton Impeller Blade and Disk Thickness on the Mixing Characteristics of Stirred Vessels, Chemical Engineering Research and Design, 74, 369-378 (1996).

Saarenrinne, P., Piirto, M. and Eloranta, H., Experiences of Turbulence Measurement with PIV*, Measurement Science and Technology, 12, 1904-1910 (2001). https://doi.org/10.1088/0957$0233 / 12 / 11 / 320$

Sagaut, P., Large Eddy Simulation for Incompressible Flows: An Introduction. Springer, Berlin (2005).

Sbrizzai, F., Lavezzo, V., Verzicco, R., Campolo, M. and Soldati, A., Direct Numerical Simulation of Turbulent Particle Dispersion in an Unbaffled Stirred-Tank Reactor, Chemical Engineering Science, 61, 2843-2851 (2006). https://doi. org/10.1016/j.ces.2005.10.073

Sharp, K. V. and Adrian, R.J., PIV Study of SmallScale Flow Structure Around a Rushton Turbine, Chemical Engineering Research and Design, 47, 766-778 (2001). https://doi.org/10.1002/ aic. 690470403 
Sheng,J., Meng, H. andFox, R.O.,AlargePIVMethod for Turbulence Dissipation Rate Estimation, Chemical Engineering Science, 55, 4423-4434 (2000). https:// doi.org/10.1016/S0009-2509(00)00039-7

Shih, T., Liou, W.W., Shabbir, A., Yang, Z. and Zhu, J., ANew k- $\varepsilon$ Eddy Viscosity Model for High Reynolds Number Turbulent Flows, Computers \& Fluids, 24, 227-238 (1995). https://doi.org/10.1016/00457930(94)00032-T

Singh, H., Fletcher, D.F. and Nijdam, J.J., An Assessment of Different Turbulence Models for Predicting Flow in a Baffled Tank Stirred with a Rushton Turbine, Chem. Eng. Sci. 66, 5976-5988 (2011). https://doi.org/10.1016/j.ces.2011.08.018

Tucker, P. and Pan, Z., A Cartesian Cut Cell Method for Incompressible Viscous Flow, Applied
Mathematical Modelling, 24, 591-606 (2000). https://doi.org/10.1016/S0307-904X(00)00005-6

Weetman, R.J. and Oldshue, J.Y., Power, Flow and Shear Characteristics of Mixing Impellers. Proceeding of 6th European Conference on Mixing. Associazione italiana di ingegneria chimica, Pavia, Italy, (1988).

Wilcox, D.C., Turbulence Modeling for CFD. DCW Industries, California (1993).

Yeoh, S.L., Papadakis, G. and Yianneskis, M., Numerical Simulation of Turbulent Flow Characteristics in a Stirred Vessel Using the LES and RANS Approaches with the Sliding=Deforming Mesh Methodology, Chemical Engineering Research and Design, 82, 834-848 (2004). https:// doi.org/10.1205/0263876041596751 